\title{
¿Commercial-Aircraft-Based Observations for NWP: Global Coverage, Data Impacts, and COVID-19
}

\author{
ERic P. JAmes, ${ }^{\mathrm{a}, \mathrm{b}}$ StANLEy G. Benjamin, ${ }^{\mathrm{b}}$ AND Brian D. JAMison ${ }^{\mathrm{c}, \mathrm{b}}$ \\ ${ }^{\text {a }}$ Cooperative Institute for Research in Environmental Sciences, University of Colorado Boulder, Boulder, Colorado; \\ ${ }^{\mathrm{b}}$ NOAA/OAR/ESRL/Global Systems Laboratory, Boulder, Colorado; ${ }^{\mathrm{c}}$ Cooperative Institute for Research in the Atmosphere, \\ Colorado State University, Fort Collins, Colorado
}

(Manuscript received 21 January 2020, in final form 18 September 2020)

\begin{abstract}
Weather observations from commercial aircraft constitute an essential component of the global observing system and have been shown to be the most valuable observation source for short-range numerical weather prediction (NWP) systems over North America. However, the distribution of aircraft observations is highly irregular in space and time. In this study, we summarize the recent state of aircraft observation coverage over the globe and provide an updated quantification of its impact upon short-range NWP forecast skill. Aircraft observation coverage is most dense over the contiguous United States and Europe, with secondary maxima in East Asia and Australia/New Zealand. As of late November 2019, 665 airports around the world had at least one daily ascent or descent profile observation; 400 of these come from North American or European airports. Flight reductions related to the COVID-19 pandemic have led to a $75 \%$ reduction in aircraft observations globally as of late April 2020. A set of data denial experiments with the latest version of the Rapid Refresh NWP system for recent winter and summer periods quantifies the statistically significant positive forecast impacts of assimilating aircraft observations. A special additional experiment excluding approximately $80 \%$ of aircraft observations reveals a reduction in forecast skill for both summer and winter amounting to $30 \%-60 \%$ of the degradation seen when all aircraft observations are excluded. These results represent an approximate quantification of the NWP impact of COVID-19-related commercial flight reductions, demonstrating that regional NWP guidance is degraded as a result of the decreased number of aircraft observations.
\end{abstract}

KEYWORDS: Aircraft observations; Sensitivity studies; Numerical weather prediction/forecasting; Short-range prediction

\section{Introduction}

Numerical weather prediction (NWP) systems depend critically upon observations of the meteorological state of the atmosphere. Both in situ and remotely sensed observations can be useful, although vertical profile observations in the troposphere are considered particularly valuable (e.g., aircraft ascent/descent observations per James and Benjamin 2017, hereinafter JB17). Atmospheric data assimilation is the mathematical process of blending information from an NWP model background with new weather observations to create the best possible starting point for a forecast (Kalnay 2002); the influence of observations on model forecast skill, through data assimilation, is particularly evident at short forecast lead times (i.e., $0-12 \mathrm{~h}$ ), becoming less important for longer forecasts from regional models (e.g., Benjamin et al. 2016).

Aircraft-based observations (ABO) are one of the most important meteorological observation sources within the modern global observing system, as determined by observation sensitivity experiments (OSEs; Cardinali 2009; JB17) as well as by the "forecast sensitivity to observation impact" technique (Langland and Baker 2004; Auligné et al. 2016). ABOs provide approximately $60 \%$ of the impact of all "conventional" observations over the United States (Petersen

¿ Denotes content that is immediately available upon publication as open access.

Corresponding author: Eric James, eric.james@noaa.gov
2016). The availability of these data played a key role in the early development of rapidly updating regional NWP systems within the United States (Benjamin et al. 1991, 2004). The original National Oceanic and Atmospheric Administration (NOAA) NWP system featuring hourly cycling [the Rapid Update Cycle (RUC)] was replaced by the next-generation Rapid Refresh (RAP) in 2012. Data assimilation and model physics advancements within the RAP NWP system have contributed to a continued increase in model forecast skill since the days of the RUC (e.g., Benjamin et al. 2016, Fig. 4a); however, the rapidly increasing availability and coverage (in both space and time) of $\mathrm{ABO}$ continues to drive a large portion of this improvement. Both of these factors suggest that regularly updated observation impact studies are warranted.

The "coronavirus disease 2019" (COVID-19) pandemic has recently led to a massive global curtailing of commercial flights and a major decrease in the spatial and temporal coverage of $\mathrm{ABO}$. This crisis has highlighted the importance of $\mathrm{ABO}$ availability for NWP data assimilation, leading to suggestions that the ongoing decreases in observation coverage could adversely impact NWP forecast skill. It is important to examine this hypothesis with carefully controlled data denial experiments.

Moninger et al. (2003) provide an overview of automated meteorological reports from commercial aircraft. At that time, data from aircraft meteorological data relay (AMDAR) constituted the largest fraction of $\mathrm{ABO}$, with data relayed to the ground by the Aircraft Communication Addressing and Reporting System (ACARS), run by Aeronautical Radio, Inc. (ARINC, now owned by Collins Aerospace), and stored 
in ARINC's Meteorological Data Collection and Reporting System (MDCRS). MDCRS distributes data from ARINC to NWP centers via the global telecommunication system (GTS). Beyond the United States, international AMDAR systems, established nationally or regionally, provide aircraft observations over other regions of the globe. In early 2020, for example, there were 14 airlines in the European AMDAR program (S. Taylor 2020, personal communication). However, increasingly in recent years, other communication methods for $\mathrm{ABO}$ transmission, such as automatic dependent surveillance-contract (ADS-C), are also becoming widespread over much of the globe. ADS-broadcast (ADS-B) equipment of aircraft for transmission of navigation data is now mandated by the U.S. Federal Aviation Administration (FAA) as of January 2020 (FAA 2010).

The tropospheric AMDAR (TAMDAR) sensor was installed in the early 2000s on smaller turboprop aircraft flying at lower altitudes and servicing smaller regional U.S. airports that are not visited by larger AMDAR jets (Daniels et al. 2006). In addition to the standard temperature and wind measurements systems, these aircraft were equipped with water vapor sensors. Moninger et al. (2010) carried out an evaluation of the quality of TAMDAR observations as well as their impact upon RUC forecast skill, finding significant positive impacts coming from the assimilation of these observations; these conclusions are supported also by the work of Zhang et al. (2015). Since the inception of TAMDAR, water vapor sensors [particularly the Water Vapor Sensing System (WVSS); Fleming 1996; Petersen et al. 2016] have been installed on some nonTAMDAR aircraft. Recent summaries of ABO format and availability are provided by the World Meteorological Organization (WMO 2019).

Additional aircraft observations have recently become available via direct tracking of aircraft by air traffic control radars (de Haan 2011; Strajnar 2012). These observations, referred to as Mode-S, represent a significant increase in the volume of aircraft observations (potentially up to two orders of magnitude), although assimilation thus far has largely been limited to Europe (de Haan and Stoffelen 2012; Strajnar et al. 2015), and they require careful consideration of the location of receivers based on airport locations, air traffic patterns, and local topography due to radar beam geometry (e.g., de Haan 2011; Stone and Pearce 2016). Mode-S observations are assimilated operationally in the Met Office "UKV" system (Met Office 2019). These emerging aircraft observation technologies are not addressed in this study.

While the quality of AMDAR temperature and wind reports has been shown to be relatively high (e.g., Benjamin et al. 1999; Ding et al. 2018), bias correction provides an opportunity to account for measurement biases. The sign and magnitude of ABO temperature biases depends upon aircraft type, pressure altitude, and phase of flight (Drüe et al. 2008), but ABO generally exhibit a warm bias (Ballish and Kumar 2008) relative to rawinsonde sensors. Zhu et al. (2015) demonstrate that a variational bias correction, specific to each aircraft tail number, can lead to slightly improved analyses and forecasts, reducing the warm bias around $200 \mathrm{hPa}$. In the RAP system, quality control is handled through a dynamic aircraft "reject list," wherein aircraft with consistently large departures from the
NWP model background are flagged for rejection from the data assimilation system. The variational bias correction method of Zhu et al. (2015) has been tested in the RAP system, but impacts were not found to be statistically significant (M. Hu 2020, personal communication).

Jamison and Moninger (2002) summarized ACARS data coverage over the contiguous United States (CONUS; i.e., the lower 48 states), pointing out that the total number of reports varies from hour to hour by more than a factor of 4 . Weekend reports amount to only about $60 \%$ of weekday reports due to package carriers not flying on weekends. The vast majority of near-surface data was provided by package carriers, because of their data format, which provided high vertical resolution at low levels. They also found the distribution of data above $25000 \mathrm{ft}$ $(7620 \mathrm{~m})$ to be fairly uniform over the CONUS, with coverage below this level concentrated near major airport hubs. Periods of poor weather, particularly ice and snow, and to a lesser extent low visibility, can greatly decrease the coverage of $\mathrm{ABO}$, even in regions distant from the actual weather event.

Petersen (2016) and Petersen et al. (2016) provide an overview of the current state of $\mathrm{ABO}$ and their use and impact within NWP systems. An increase in observing frequencies during the late 1990s was motivated by early studies of ABO impacts on regional NWP systems; observations began to be taken every $10 \mathrm{hPa}$ in the lowest $100 \mathrm{hPa}$ during takeoff and every $50 \mathrm{hPa}$ up to $400 \mathrm{hPa}$ (WMO 2003), with positive observation impacts demonstrated in various global systems (e.g., Langland and Baker 2004; Lorenc and Marriott 2013; Buehner et al. 2018). Other initial studies using the RUC model indicated similar positive impacts (e.g., Benjamin et al. 2010). In a broader study summarizing global NWP tests from various centers (Petersen 2016), ABO were found to be the third-mostimportant observation type overall. Impacts for individual events have been found to sometimes be larger than longerterm averages (e.g., Hoover et al. 2017).

The purpose of this article is twofold. First, we aim to summarize the current spatial and temporal distribution of $\mathrm{ABO}$ globally, with a particular focus over North America (Canada, the United States, Mexico, and Central America), and from the perspective of availability for assimilation into a rapidly updating NWP system. Second, we aim to quantify the impact of assimilating $\mathrm{ABO}$, including the impact of decreases in $\mathrm{ABO}$ volume such as has occurred during the ongoing COVID-19 crisis. Our experiments build upon the results of JB17, providing updated OSEs using the latest version of the RAP NWP system [RAPv5, slated for implementation at the National Centers for Environmental Prediction (NCEP) in late 2020] for recent summer and winter seasons, and including TAMDAR observations for the first time. Several non-peer-reviewed articles (e.g., ECMWF 2020; Henson et al. 2020) have speculated that a partial ABO outage would lead to an NWP forecast degradation, and a recent study by Chen (2020) suggests that recent real-time forecast degradations are attributable to the ongoing ABO reductions; however, our results represent the first controlled quantification of this impact for regional NWP.

The following section details observation coverage, with some consideration of the diurnal cycle of ABO coverage, as 

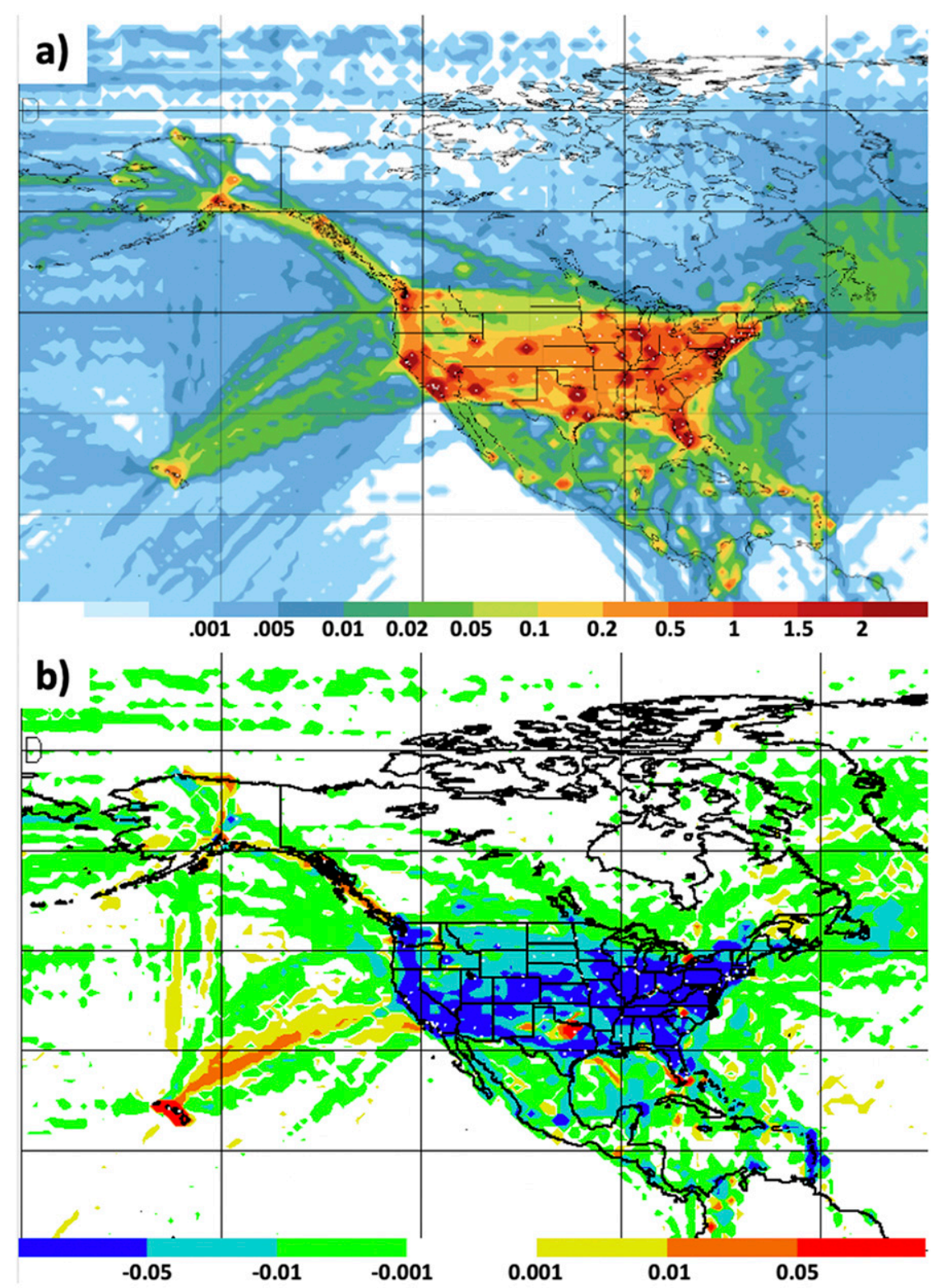

FIG. 1. North American ABO coverage (number of monthly observations per kilometer squared) during (a) March 2019, and (b) the difference in coverage between March 2019 and March 2020. Small white dots indicate CONUS airport locations.

well as recent trends in $\mathrm{ABO}$ across the globe, and impacts of the COVID-19 pandemic. Quantification of ABO impact due to assimilation within the RAP NWP system is provided in the next section. The concluding section contains some discussion of the results, and directions for future research.

\section{Current state of $\mathrm{ABO}$ coverage}

In this section, we outline the pre-COVID-19 (March 2019) and during COVID-19 (March 2020) coverage of ABO in the four dimensions of space and time. We begin with an overview of coverage over North America, followed by a summary of global coverage.

\section{a. ABO coverage over North America}

Figure 1 presents the total coverage and density of ABOs during March 2019 (Fig. 1a), as well as the change in ABO coverage from March 2019 to March 2020 (Fig. 1b). A month is considered a sufficiently long period to average across day-to-day variabilities, although it is important to consider differences in the number of weekend days versus weekdays; March 2019 contained 10 weekend days, whereas March 2020 contained 9. Note that these maps include all AMDAR and ADS-C data (see preceding section). The units are the number of observations per kilometer squared, with the analysis conducted on a $1^{\circ}$ latitude by $1^{\circ}$ longitude grid. Because of this 


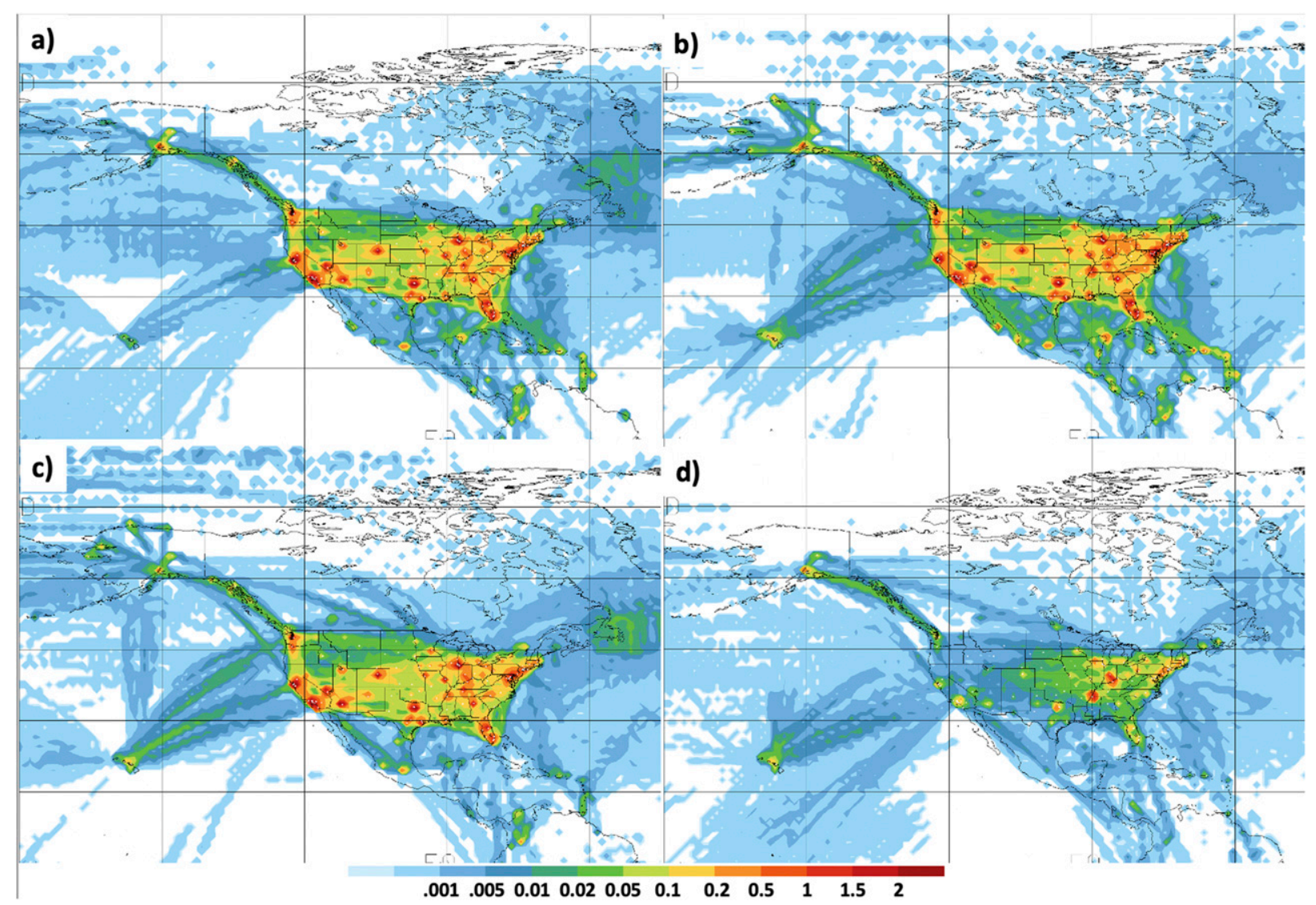

FIG. 2. North American ABO coverage (number of monthly observations per kilometer squared) in March 2019 for (a) 1200-1800, (b) 1800-0000, (c) 0000-0600, and (d) 0600-1200 UTC. Small white dots indicate CONUS airport locations.

relatively coarse grid, even near busy airports the ABO coverage remains below 1-2 per kilometer squared. Excluding potential global holidays that have moved in and out of the month of March, and the difference in number of weekdays, differences between these months can be attributed to one of the following factors: (i) differences in flight tracks due to differences in meteorology (e.g., jet stream latitude), (ii) human or economic influences upon aircraft traffic, or (iii) changes in number of reporting aircraft (e.g., addition of new airlines to AMDAR programs). Consistent with previous studies, the highest concentrations of ABOs are located near major airport hubs, particularly over much of the southern United States, eastern United States, and West Coast; along the western coast of Canada and Alaska; and in central Hawaii. Major North American flight routes can be readily identified, particularly routes from West Coast hubs to Hawaii and Alaska, flights to the Caribbean, and transatlantic flights. Coverage over southern Quebec and the Canadian Maritime provinces is considerable because of high aircraft traffic between the eastern CONUS and Europe, and there is also good coverage along a swath from the interior eastern CONUS to Alaska. However, far southwestern Canada (southern British Columbia) as well as northern Manitoba and Quebec have relatively few reports. Regions with the fewest reports (within the North American region) include the northern Pacific-Gulf of Alaska region, the
Canadian Arctic, and especially the tropical eastern Pacific Ocean. Within the CONUS, there is substantially reduced coverage of ABOs over a broad region from the northern intermountain region into the northern plains, and more substantial gaps in northern Mexico (particularly along the western Texas-Mexico border) and both southwestern and southeastern Canada (extending into northern Minnesota and Michigan).

There are major decreases in ABO coverage over much of the North American region between March 2019 and 2020 (Fig. 1b). U.S. flight reductions related to COVID-19 began in mid-March 2020. Coverage over North America broadly decreased by at least 0.001 observations per kilometer squared in most areas, with coverage over most CONUS locations decreasing by at least 0.01 observation per kilometer squared. As expected, larger decreases are associated with regions of higher average coverage in March 2019 (Fig. 1a). There are isolated regions where coverage was higher in March 2020 than in March 2019 (e.g., the Dallas-Fort Worth, Texas, vicinity, as well as Hawaii and flight routes between Hawaii and California). It is possible that the effect of more weekdays during March 2020 than March 2019 is offsetting the decrease in coverage related to COVID-19 in these regions.

Separating out the March 2019 results by time of day, Fig. 2 shows ABO coverage broken down into four 6-h periods. The 1200-1800 UTC period (Fig. 2a) represents morning over the 


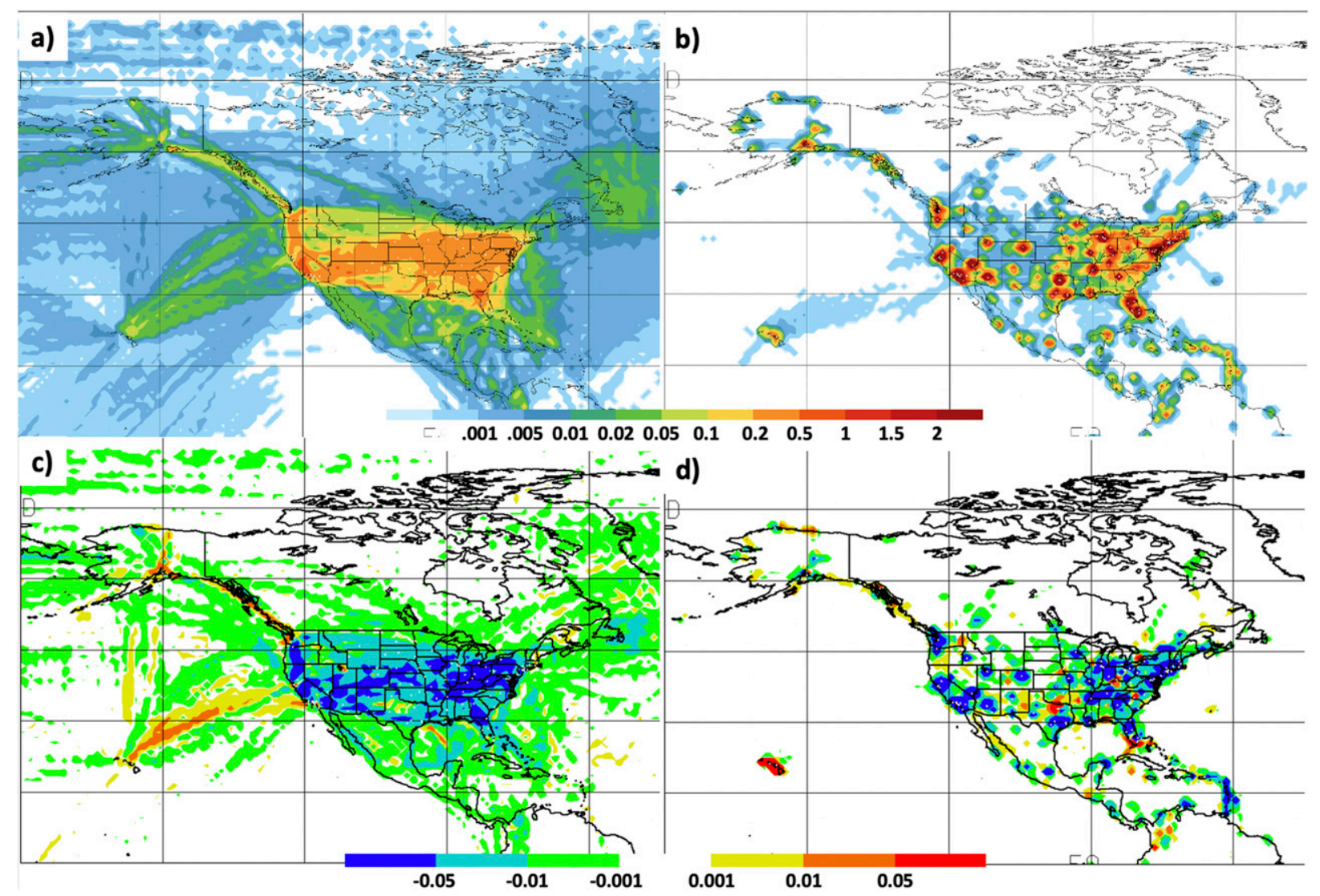

FIG. 3. North American ABO coverage (number of monthly observation per kilometer squared) at pressures (a),(c) less than $350 \mathrm{hPa}$ and (b),(d) greater than $350 \mathrm{hPa}$ for (top) March 2019 and (bottom) the difference in coverage between March 2019 and March 2020. Small white dots indicate CONUS airport locations.

central CONUS; during this time of day, coverage is focused largely over the CONUS itself, with some contributions from westbound flights over the North Atlantic Ocean and flights to and from Alaska. During the afternoon period (Fig. 2b; 1800-0000 UTC), fewer transatlantic flights appear, but there is increased data coverage from flights to Hawaii and Alaska, as well as the Caribbean and Central America. In the evening period (Fig. 2c; 0000-0600 UTC), eastbound transatlantic flights provide good coverage over the North Atlantic once again, and routes to Alaska and Hawaii have good coverage. Finally, in the overnight time period (Fig. 2d; 0600-1200 UTC), coverage is substantially reduced over most of the continent. The notable exception to this pattern is the continued coverage of ABOs near the package-carrier central hubs of Memphis, Tennessee, and Louisville, Kentucky. Some busier East Coast airports also retain substantial coverage during this overnight time period, and overnight flight routes to Alaska and Hawaii remain evident.

The ABO coverage dataset can also be interrogated by phase of flight; that is, separating reports from ascending aircraft versus those from descending aircraft, and ascent/descent versus en route reports. Here we use the pressure threshold of $350 \mathrm{hPa}$ (approximately $26500 \mathrm{ft} \mathrm{MSL}$, or $8077 \mathrm{~m}$ ) to separate cruising from ascent/descent aircraft. Figures $3 \mathrm{a}$ and $3 \mathrm{c}$ show only ABO coverage from en route aircraft during March 2019 (Fig. 3a) and the difference between en route coverage in March 2019 and in March 2020 (Fig. 3c). While coverage remains greatest in the vicinity of busy airport hubs, en route coverage does not highlight airports as bullseyes due to the exclusion of the ascent/descent portion of the flights. These maps highlight domestic and international flight routes, as well as notable regions with nonexistent $\mathrm{ABO}$ coverage such as the high Arctic and especially the tropical eastern Pacific Ocean.

Figures $3 \mathrm{~b}$ and $3 \mathrm{~d}$ map the coverage of $\mathrm{ABO}$ from ascending and descending aircraft. The map of March 2019 ascending/descending observations illustrates the location of valuable vertical profile observations from aircraft in the vicinity of airports, although some lower altitude cruising routes are also apparent (e.g., between the West Coast of the CONUS and Hawaii, and over northern Quebec; Fig. 3b). Notable gaps in vertical profile coverage include a swath from southern Oregon/northern California eastward toward Salt Lake City, Utah; the northern intermountain region of Idaho, Montana, and Wyoming; and especially the northern plains (eastern Montana into the Dakotas, extending into northern Minnesota, Wisconsin, and Michigan). Outside of the immediate CONUS region, almost all of Canada is unobserved, together with the deserts of northern Mexico, and obviously all of the surrounding oceanic regions. As of late 


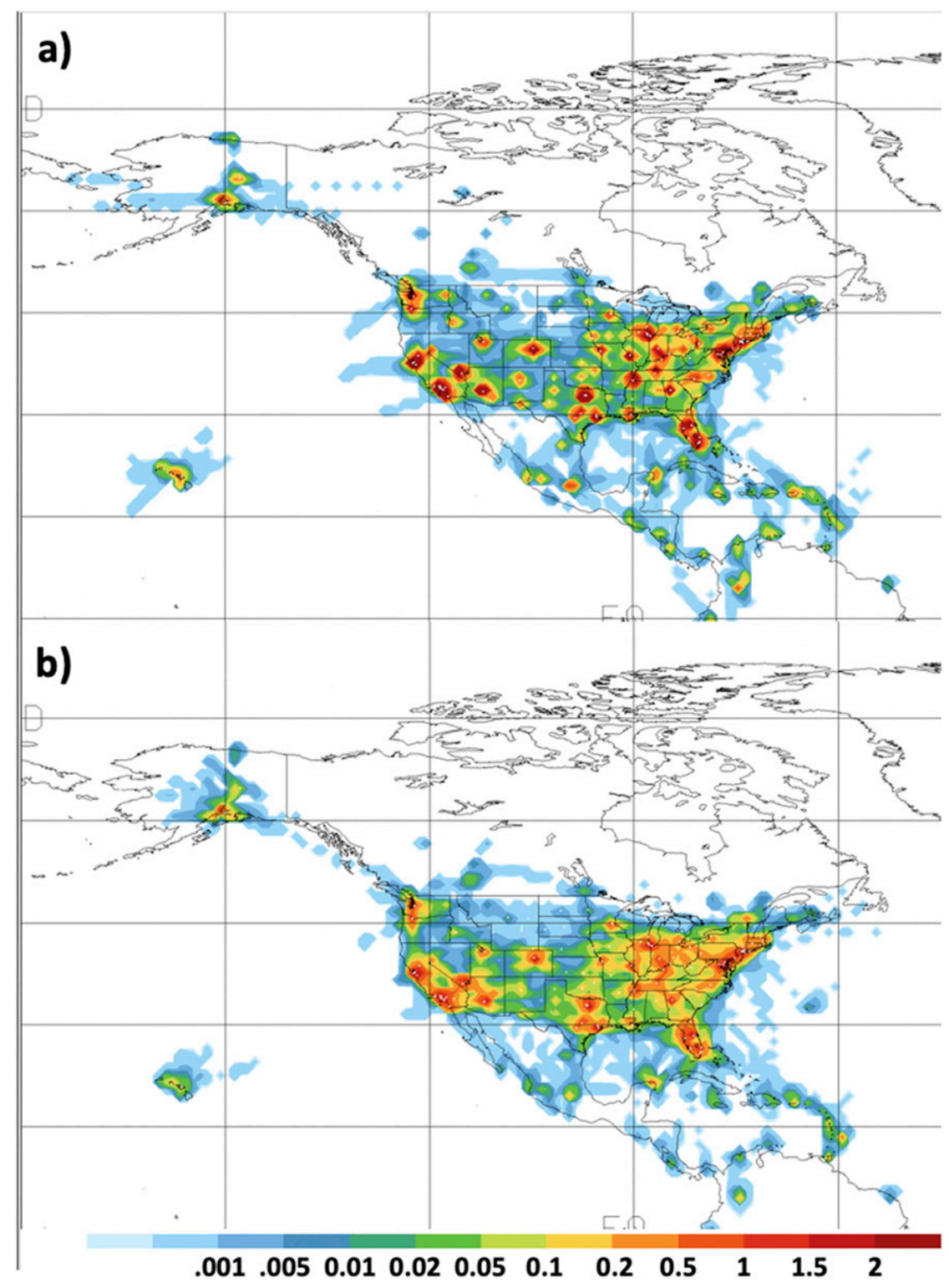

FIG. 4. North American ABO coverage (number of monthly observations per kilometer squared) in March 2019 of ABO taken in (a) ascending and (b) descending flight phase. Small white dots indicate CONUS airport locations.

November 2019, 250 airports in North America had at least one daily ascent or descent profile observation. Most airports have reduced coverage in March 2020 than in March 2019 (Fig. 3d), and there is also a decrease in en route observation coverage (Fig. 3c).

Figure 4 shows the difference in ABO coverage from flights in the ascending phase versus the descending phase of flight. Since aircraft ascend much steeper than they descend, coverage of ascending $\mathrm{ABO}$ is generally limited to a small radius in the immediate vicinity of airports (Fig. 4a). However, descending ABO cover larger areas, generally along a vector from a single direction (Fig. 4b).

It is important to note that exact flight routes vary considerably on the basis of weather situations, both for route optimization and for hazard avoidance. Thus, while the general patterns presented here can be expected to represent a mean ABO coverage state, details of the exact flight routes will vary from day to day. ABO coverage patterns also vary slightly between weekdays and weekends; however, the differences are generally small (not shown).

\section{b. Global ABO coverage}

Figure 5 presents global ABO coverage during March 2019 (Fig. 5a), and the difference between March 2019 and March 2020 (Fig. 5b). International flight routes stand out prominently, in addition to regions where air traffic is very sparse or nonexistent. The greatest traffic routes are between North America 


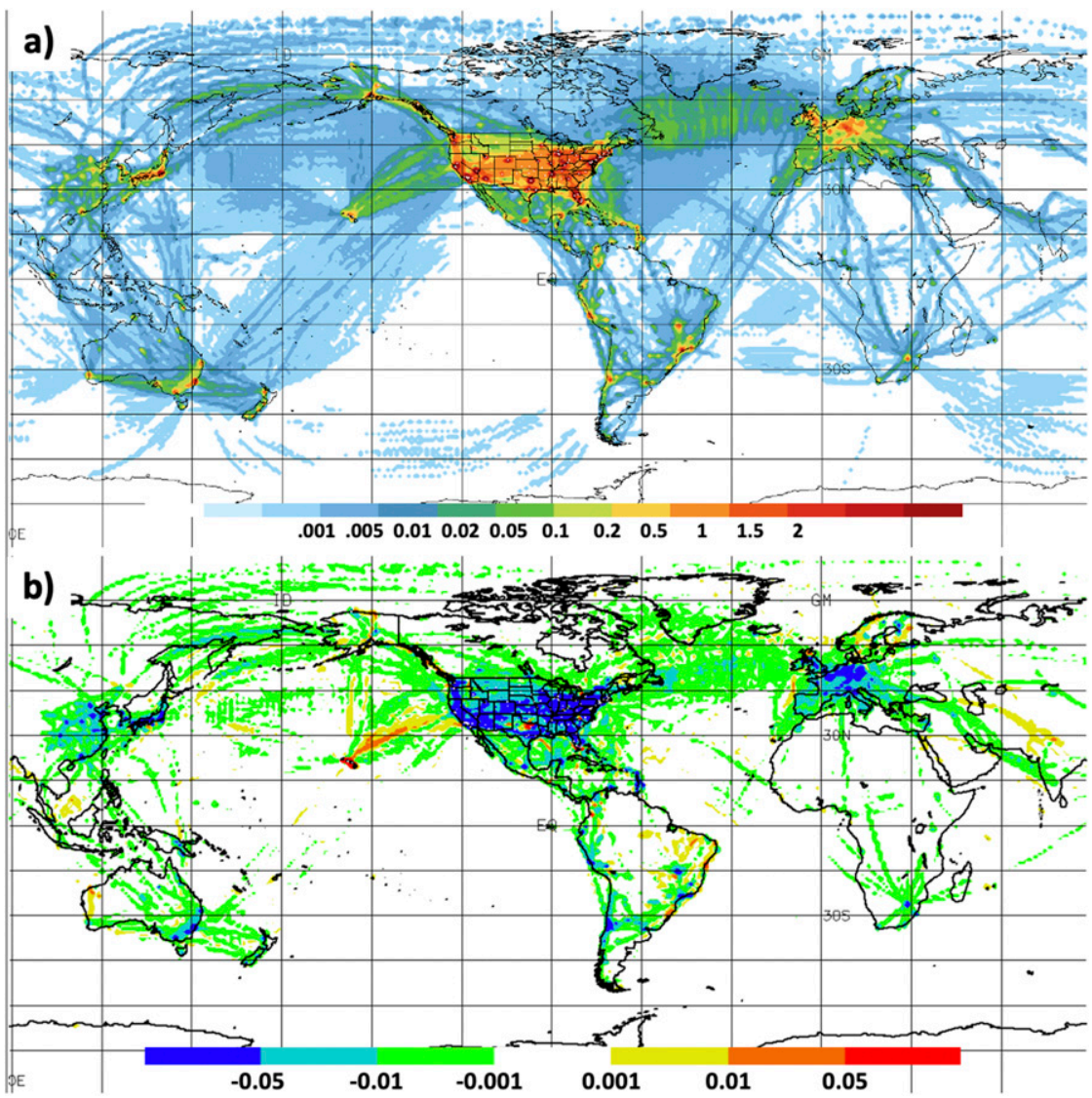

FIG. 5. Global ABO coverage (number of monthly observations per kilometer squared) (a) during March 2019, and (b) the difference in coverage between March 2019 and March 2020. Small white dots indicate CONUS airport locations.

and Europe, with secondary maxima between the CONUS and Hawaii and from the West Coast to eastern Asia. Other intercontinental flight routes are more localized, although there is substantial traffic between Australia and New Zealand. Note that the meridional lines of higher ABO counts seen in the North Atlantic are real, produced by automated ADS-C reports on intercontinental flights being triggered at discrete time intervals (so-called periodic contracts; P. Pauley 2020, personal communication). Figure $5 \mathrm{~b}$ reveals the global extent of COVID-19 flight reductions. Decreases in report coverage between March 2019 and March 2020 are seen all over the world, with the magnitude of the decrease related to the overall aircraft traffic in each region. Small increases in coverage are seen for certain flight routes and airports.

The diurnal cycle of ABO coverage varies as would be expected around the globe (Fig. 6), with most ABO coverage following the sun. The departure and arrival schedules of typical transcontinental flight routes can be discerned; for example, the region of high ABO coverage in the North Atlantic in the 0000-0600 UTC period (Fig. 6c) has shifted eastward toward Europe by the 0600-1200 UTC period (Fig. 6d). Other such flight groupings are evident around the world. In general, it appears that only the busiest of airports and long-haul flight routes retain coverage during the overnight period.

The coverage of en route ABO (Figs. 7a,c) shows the major international flight routes where cruising aircraft are relatively common. A map of ascending/descending phased ABO around the world (Figs. 7b,d) highlights just how sparse the coverage of these observations is, once cruising observations are excluded. Once again, ABO coverage reductions are seen between March 2019 and March 2020 for both en route (Fig. 7c) and ascending/descending (Fig. 7d) phase of flight. Figure 8 illustrates the coverage of ascending (Fig. 8a) and descending (Fig. 8b) global ABO. The tendency for broader coverage of descending observations is not as prominent globally as was seen for the North American region (Fig. 4), likely due to differing frequency of observations by region; for example, E-AMDAR optimizes the frequency of profile observations based upon local national meteorological service requirements and the baseline requirements for the European Meteorological Network (EUMETNET) program (EUMETNET 2015).

Gigantic data voids exist over most continental regions outside of the CONUS, Europe, and eastern Asia (Figs. 7, 8). This highlights the potential value of obtaining new observations from 


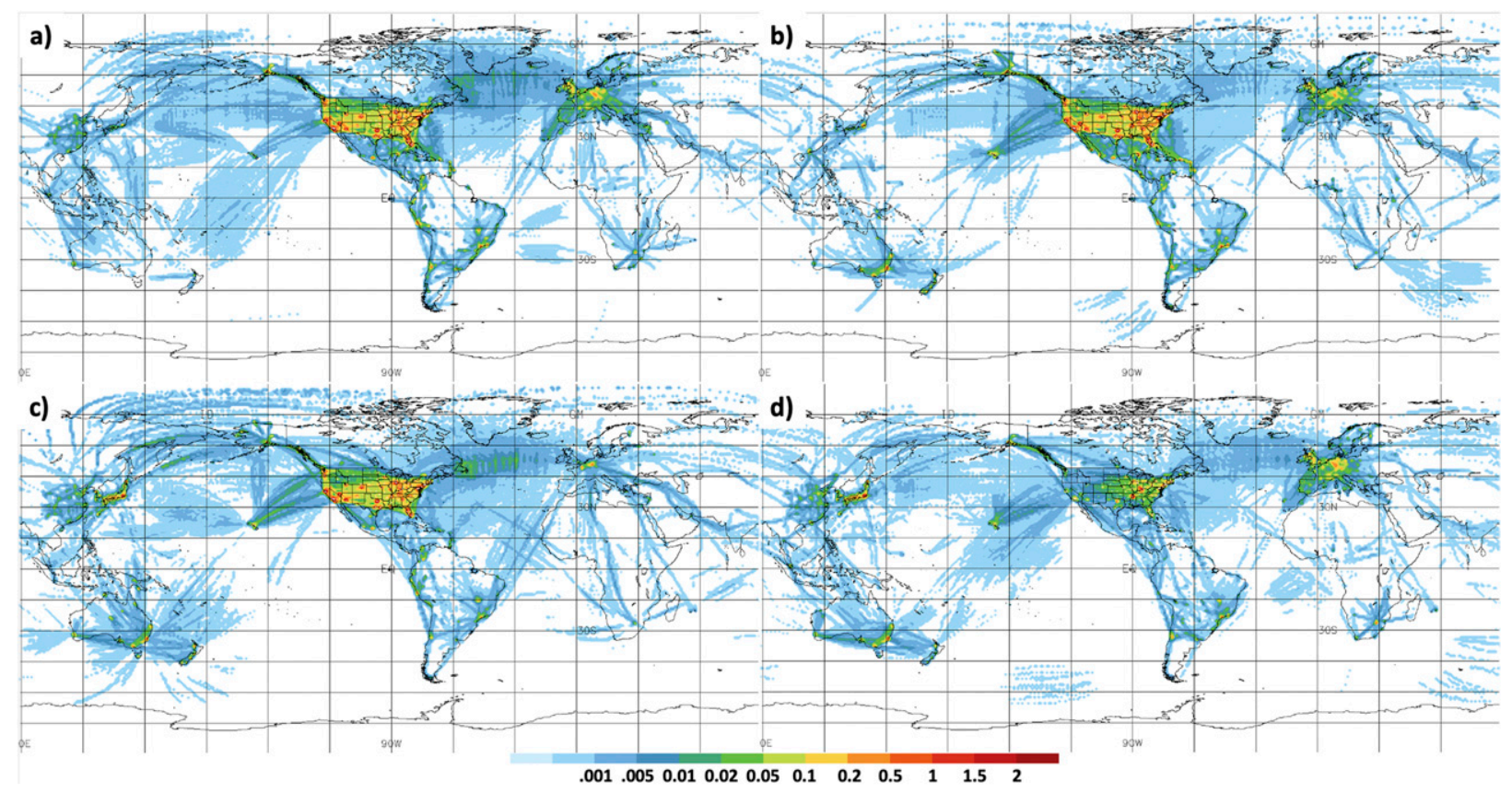

FIG. 6. Global ABO coverage (number of monthly observations per kilometer squared) in March 2019 for (a) 1200-1800, (b) 1800-0000, (c) 0000-0600, and (d) 0600-1200 UTC. Small white dots indicate CONUS airport locations.

airlines servicing smaller airports around the world; the ongoing Kenyan AMDAR project is an example of such an effort (WMO 2015). Globally, as of late November 2019, 665 airports had at least one daily ascent or descent profile observation; 400 of these come from North American or European airports.

\section{c. Coverage decreases as a result of COVID-19}

The COVID-19 pandemic in 2020 has led to a large reduction in the frequency of commercial flights around the world. Decreases have followed the global spread of the COVID-19 virus and associated lockdown measures employed to contain

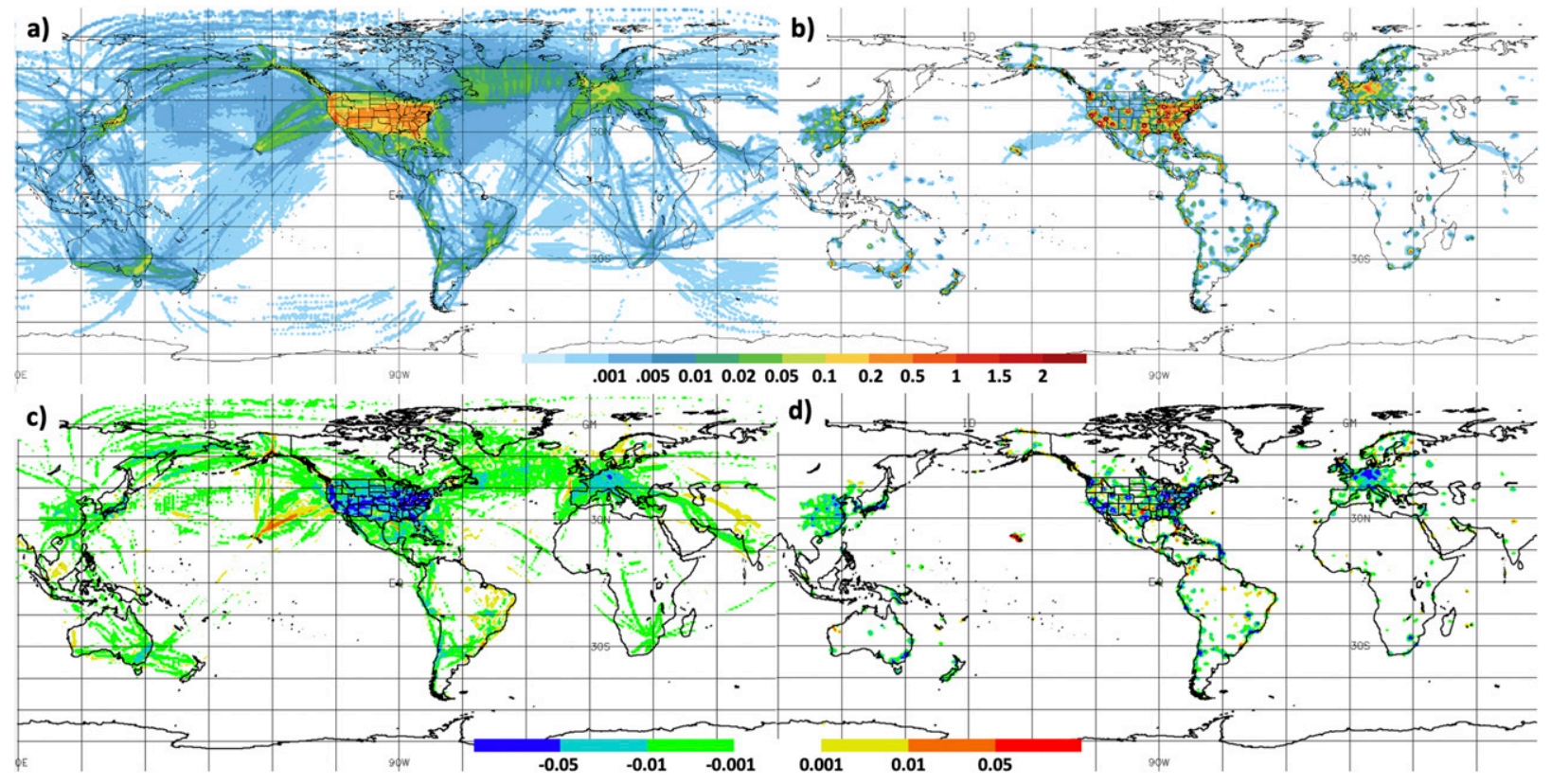

FIG. 7. Global ABO coverage (number of monthly observations per kilometer squared) at pressure (a), (c) less than $350 \mathrm{hPa}$ and (b), (d) greater than $350 \mathrm{hPa}$ for (a),(b) March 2019 and (c),(d) the difference in coverage between March 2019 and March 2020. Small white dots indicate CONUS airport locations. 


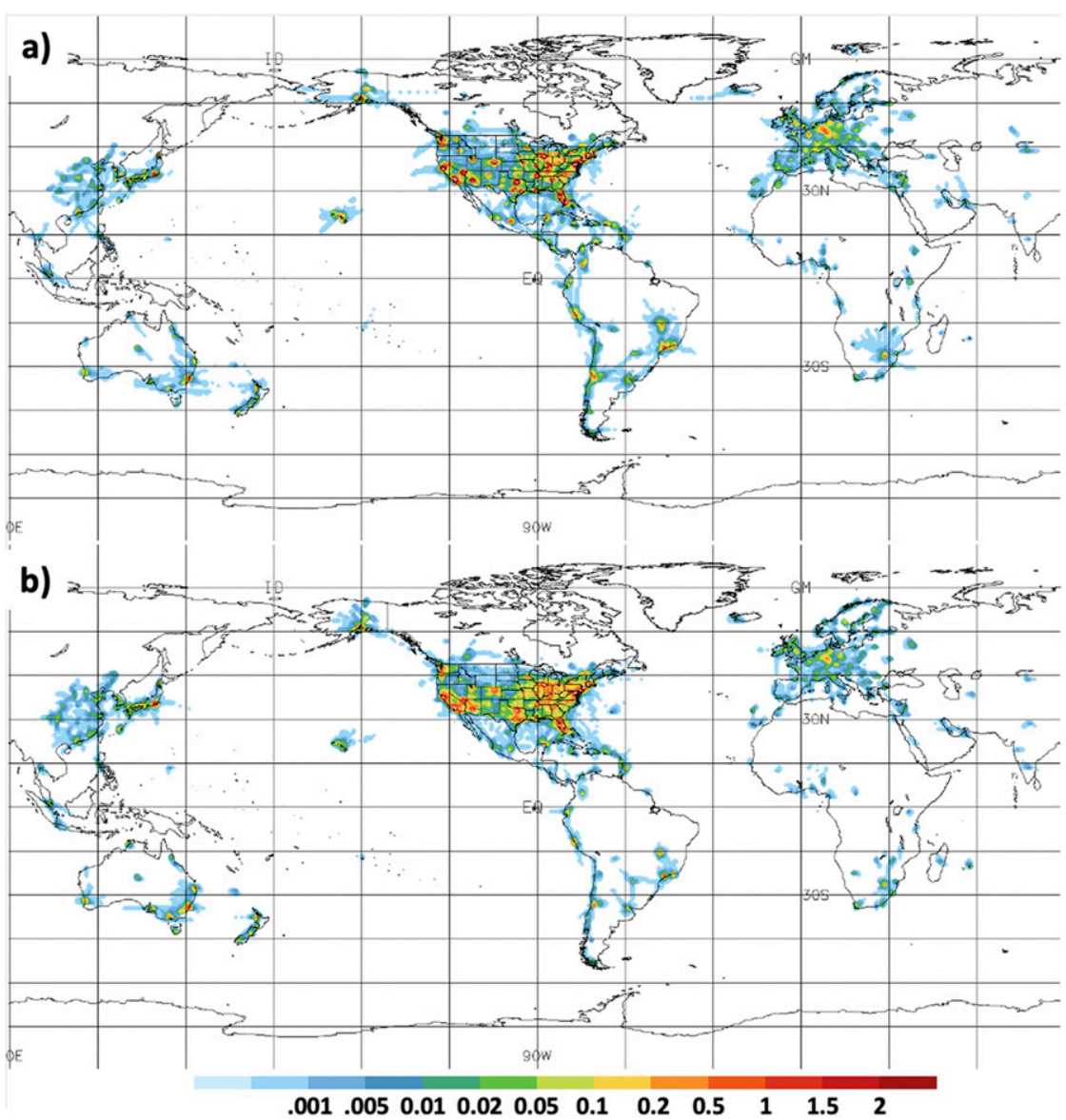

FIG. 8. Global ABO coverage (number of monthly observations per kilometer squared) in March 2019 of ABO taken in (a) ascending and (b) descending flight phase. Small white dots indicate CONUS airport locations.

the virus. As of late April 2020, some countries, for example, Argentina, have halted commercial flights entirely. It is anticipated that reduced levels of ABO coverage will continue through at least the remainder of 2020.

Figure 9 shows a time series of the number of ABO globally and over the CONUS region by week since the beginning of 2020. Also illustrated are the observation counts above and below $26500 \mathrm{ft}$ for each region, approximately separating cruising observations from ascending/descending observations. Sudden observation reductions are seen globally and over the United States beginning the week of 11 March 2020. The rate of decrease slowed during the week of 25 March, but steady decreases continued for the following month. As of the end of April, coverage was at $25 \%$ of pre-COVID-19 levels globally and over the U.S. domain. The number of reports seems to have stabilized in late April.

\section{Aircraft OSEs using the latest RAP assimilation/forecast system}

To determine the ABO coverage needed for NWP optimization, it is important to understand the nature of the relationship between coverage and resultant forecast skill.
Here we extend the work of JB17 to carry out an additional set of data denial experiments (OSEs) using the latest version of the RAP system, RAPv5, scheduled for operational implementation at NOAA's NCEP in 2020 (JB17 used the earlier RAP version, RAPv3). The tests are carried out for two recent 10-day retrospective periods (July 2018 and February 2019) so as to represent the near-current spatiotemporal distribution of observations being assimilated in the RAP system. Here we present differences in forecast error [using the difference in root-mean square error (RMSE)] for wind, temperature, and relative humidity $(\mathrm{RH})$ as verified against rawinsondes, calculated between a control run (assimilating all observations) and systematic denial experiments (where one observation type was denied from the assimilation). Note that RMSE includes, in fact, contributions from both observation and model error. Time series of forecast impacts (not shown) are examined to ensure temporal consistency during the retrospective periods. It is important to note that these OSEs consider the impact of regional data assimilation only, not the impact of observations from global data assimilation coming through the lateral boundaries, so we likely underestimate the true observation impacts. 


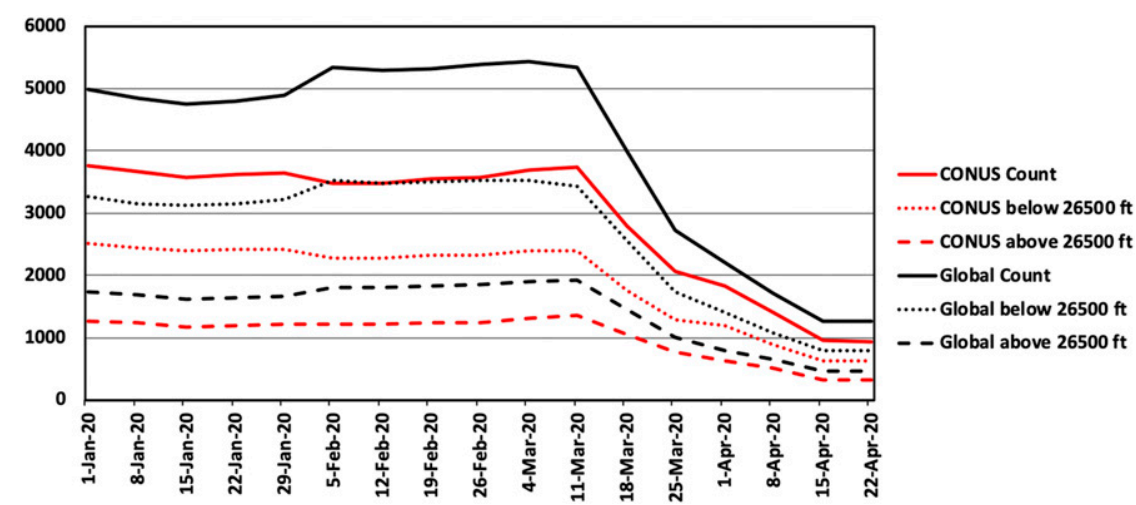

FIG. 9. Time series of weekly ABO counts globally (black) and over the CONUS (red) during 2020. Also shown are ABO counts below (dotted) and above (dashed) $26500 \mathrm{ft} ; 26500 \mathrm{ft}$ is approximately $350 \mathrm{hPa}$.

In addition, to examine the potential impact of COVID-19related $\mathrm{ABO}$ coverage decreases, we carry out a special experiment in which only aircraft with tail numbers corresponding to FedEx, Inc., flights are assimilated. Some FedEx tail number aircraft have been sold to other airlines, so some WVSS-II moisture observations are assimilated in this experiment even though FedEx aircraft are not equipped with WVSS-II sensors. Averaging over each hour of the two 10-day retrospective periods, this corresponds to an approximate $80 \%$ reduction in $\mathrm{ABO}$ as compared with the full $\mathrm{ABO}$ dataset for the variables of wind, temperature, and moisture. The experiment, hereinafter referred to as the reduced-ABO experiment, does not perfectly match what happened in truth, in part because of the somewhat unusual (more nocturnal) scheduling of FedEx flights; however, this experiment is intended to approximately represent the real observational network available for assimilation as of late April 2020. Excluding observations from a retrospective period during which we have all aircraft observations available is the only way to carry out a controlled experiment that quantifies the impact of a partial ABO outage. The detection of any true degradation in real-time NWP forecast skill during the COVID-19 ABO decrease is masked by day-to-day and yearto-year weather variability, precluding a controlled experiment comparison.

Following the convention of JB17 (p. 2904), we present RMSE differences in the form of "candlestick" plots, wherein the colored bars indicate the magnitude of the forecast degradation stemming from the exclusion of each observation type, and the thin black vertical lines indicate the range of 1 standard error [in this case, the $68 \%$ confidence interval; i.e., Benjamin et al. (2010), based on the number of forecast events and observations for each event]. In the following discussion, positive differences indicate that RMSEs are increased (i.e., forecasts are degraded) when that observation type is denied; that is, assimilation of that observation type improves the forecasts. Four "candlesticks" are shown for each observation type, corresponding to 3-, 6-, 9-, and 12-h forecast verification; the verification is against rawinsondes, using observations every $10 \mathrm{hPa}$, over various spatial domains.
As described by JB17 (p. 2903) and Moninger et al. (2010, 639-640), we also estimate the forecast error reduction percentage by examining error statistics for the RAP. For each control simulation, the maximum possible forecast error reduction is approximated as the difference in fit to rawinsonde observations between 6-h RAP forecasts and $0 \mathrm{~h}$ RAP analyses (i.e., maximum RMSE reduction $=6$-h RAP forecast RMSE - 0-h RAP analysis RMSE). This difference is used to estimate an approximate $25 \%$ reduction in forecast error for wind, temperature, and $\mathrm{RH}$, which is indicated in each plot by a black dashed horizontal line.

The interpretation of the next several figures is somewhat nonintuitive, so here we walk through their interpretation. The height of the groups of colored bars indicates the relative impact of that observation type, as compared with the impacts of other observation types. For an individual observation type, the magnitude of the impact can be followed from left to right from shorter forecast lengths (3-h forecasts) to longer forecast lengths (12-h forecasts). In general, one would expect greater observation impacts at shorter forecast ranges due to temporal proximity to the data assimilation time, which would appear as decreasing bar heights with increasing forecast length. However, the length of time since data assimilation is more complicated in the RAP system because of the timing of its twice-daily partial cycling from Global Forecast System (GFS) initial conditions (illustrated in Fig. 10), as well as the timing of the rawinsonde observations used for verification. For example, 3 -h forecasts valid at 1200 UTC (initialized at 0900 UTC) represent $7 \mathrm{~h}$ of observation use within the RAP (six during the partial cycle from 0300 to 0800 UTC, and once for the full cycle at 0900 UTC); older observations only have an influence through the GFS initial conditions introduced at 0300 UTC. A 6-h forecast valid at 1200 UTC, on the other hand, represents $16 \mathrm{~h}$ of observation use within the RAP (six during the partial cycle from 1500 to 2000 UTC on the previous day, and 10 during the ensuing full cycles from 2100 UTC until 0600 UTC). RAP forecasts distributed to downstream users come from the full cycle. These details modulate the decrease in observation impact with increasing forecast length. For instance, observation impact is often stronger 


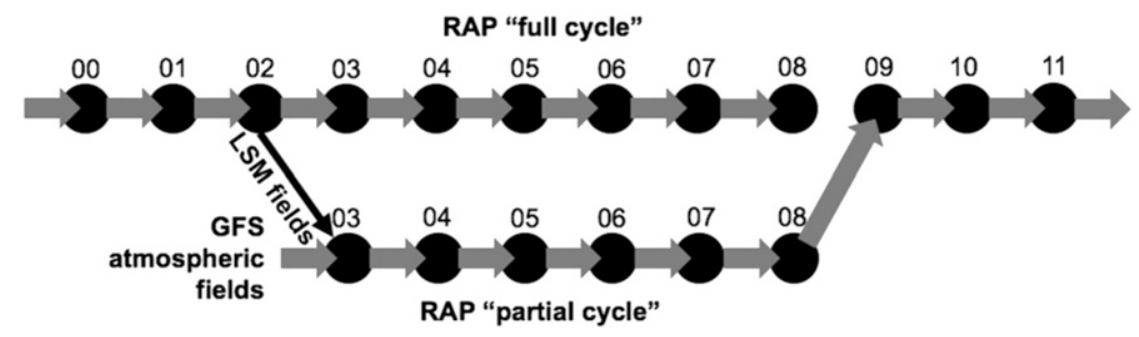

FIG. 10. Configuration of the RAP partial cycling. Black circles represent the RAP data assimilation with a background supplied by a prior forecast (represented by the gray arrows). At 0300 UTC, a parallel "partial cycle" is initialized from GFS atmospheric fields but using the full-cycle land surface model (LSM) state. A background from this partial cycle is used for the data assimilation in the primary "full cycle" $6 \mathrm{~h}$ later, at $0900 \mathrm{UTC}$. The procedure is repeated during 1200-2300 UTC.

for 6-h forecasts than for 3-h forecasts (the results described below). An additional consideration is the number of observations of each type; rawinsondes are taken only every $12 \mathrm{~h}$, averaging approximately 1630 observations per 12-h period for both summer and winter, whereas ABO amount to approximately 23000 observations every hour. On average, $60 \%$ of rawinsonde observations are below $350 \mathrm{hPa}$ (or approximately $26500 \mathrm{ft}$ ), with $40 \%$ above that level. As can be seen from Fig. 9, about $65 \%$ of ABO are below $26500 \mathrm{ft}$, with $35 \%$ of $\mathrm{ABO}$ above that level.

Figure 11 shows the integrated forecast impact of aircraft observations for temperature, relative humidity, and vector wind, over the CONUS. This region contains, on average, about 88 rawinsondes reporting during each 12-h period. Again, the positive bars indicate that the RMSE is higher without aircraft data. Figures 11a,c,e show summer impacts, and Fig. 11b,d,f show winter impacts. It is evident that aircraft observations (pink bars) have a statistically significant impact for all three variables during both summer and winter, with impacts larger than that found for rawinsonde observations; this is likely partially due to the greater number of aircraft observations. In the absence of aircraft observations, temperature forecast RMSE is increased by about $0.07 \mathrm{~K}$ for all forecast lengths to $12 \mathrm{~h}$ in summer (Fig. 11a), and by $0.13 \mathrm{~K}$ for 3- and 6-h forecasts in winter (Fig. 11b); relative humidity forecast RMSE is increased by up to $0.8 \%$ (Figs. 11c,d); and wind forecast RMSE is increased by up to $0.3 \mathrm{~m} \mathrm{~s}^{-1}$ during the summer (Fig. 11e) and by up to $0.45 \mathrm{~m} \mathrm{~s}^{-1}$ during the winter (Fig. 11f). ABO at pressure greater than $350 \mathrm{hPa}$ (green bars) contribute almost all of the relative humidity forecast impact in the CONUS domain (Figs. 11c,d), while ABO above and below $350 \mathrm{hPa}$ contribute approximately equally to wind forecast impacts (Figs. 11e,f). Over this large domain, there is a negligible contribution from TAMDAR observations (red bars), although aircraft moisture observations (purple bars) do contribute statistically significantly to $\mathrm{RH}$ forecast skill in both seasons (Figs. 11c,d). TAMDAR observations are relatively sparse in spatial and temporal coverage, so impacts tend to be small over large regions. The reader is referred to Fig. 7 of JB17 for comparison with impacts of other observation types. The reduced-ABO experiment results in a forecast degradation of less than $80 \%$ of the no-ABO experiment for most variables; in particular, temperature forecast RMSE is increased by about 0.02-0.03 K (Figs. 11a,b) and vector wind RMSE is increased by about $0.1 \mathrm{~m} \mathrm{~s}^{-1}$ in the reduced-ABO experiment (Figs. 11e,f), whereas temperature RMSE is increased by about $0.05-0.14 \mathrm{~K}$ and vector wind RMSE is increased by about $0.15-0.45 \mathrm{~m} \mathrm{~s}^{-1}$ in the no-ABO experiment.

Figure 12 shows RH forecast RMSE impacts for the experiments over the CONUS region, and for the $1000-600-\mathrm{hPa}$ layer. A statistically significant fraction of the total $\mathrm{RH}$ forecast impact of $\mathrm{ABO}$ (pink bars) comes from actual aircraft moisture observations (purple bars), which are only taken on a subset ( $\sim 15 \%$ of U.S. AMDAR data) of actual aircraft. However, it is evident that there is some nonzero $\mathrm{RH}$ forecast impact attributable to aircraft temperature and wind observations. For forecasts verified at 0000 UTC (representing initialization times generally during the daylight hours), there is a marked decrease in observation impact with increasing forecast lead time, particularly for aircraft humidity observations (purple bars, Figs. 12a,b); this is likely associated with diurnal warming and mixing out of the planetary boundary layer (PBL) during forecasts initialized during the daytime, rendering older humidity information irrelevant. In contrast, for forecasts verified at 1200 UTC (and initialized at night), longer forecasts are just as degraded as short forecasts when aircraft humidity observations are denied (Figs. 12c,d). Aircraft moisture observations appear to provide the most value (relative to the total $\mathrm{ABO}$ impact) for summertime forecasts verified at 1200 UTC (Fig. 12c). TAMDAR observations (red bars) have only a small impact on relative humidity forecasts over the CONUS. In the case of summertime RH forecasts (left column), the reduced-ABO experiment leads to an increase in RMSE that amounts to $80 \%$ or more of the impact from excluding all aircraft observations. Impacts of the reduced ABO coverage are smaller for winter RH (right column), but still relatively larger than seen for other variables. This suggests that forecast degradations due to reduced flight coverage may be seen more prominently in $\mathrm{RH}$ forecasts.

In Fig. 13, we present forecast impacts over the Alaska region. Note that this verification region contains 14 upper-air sites. It is evident that the statistical significance of the results is somewhat mixed, partially due to the limited number of upperair sites in this region. Overall, ABO provide forecast benefits 

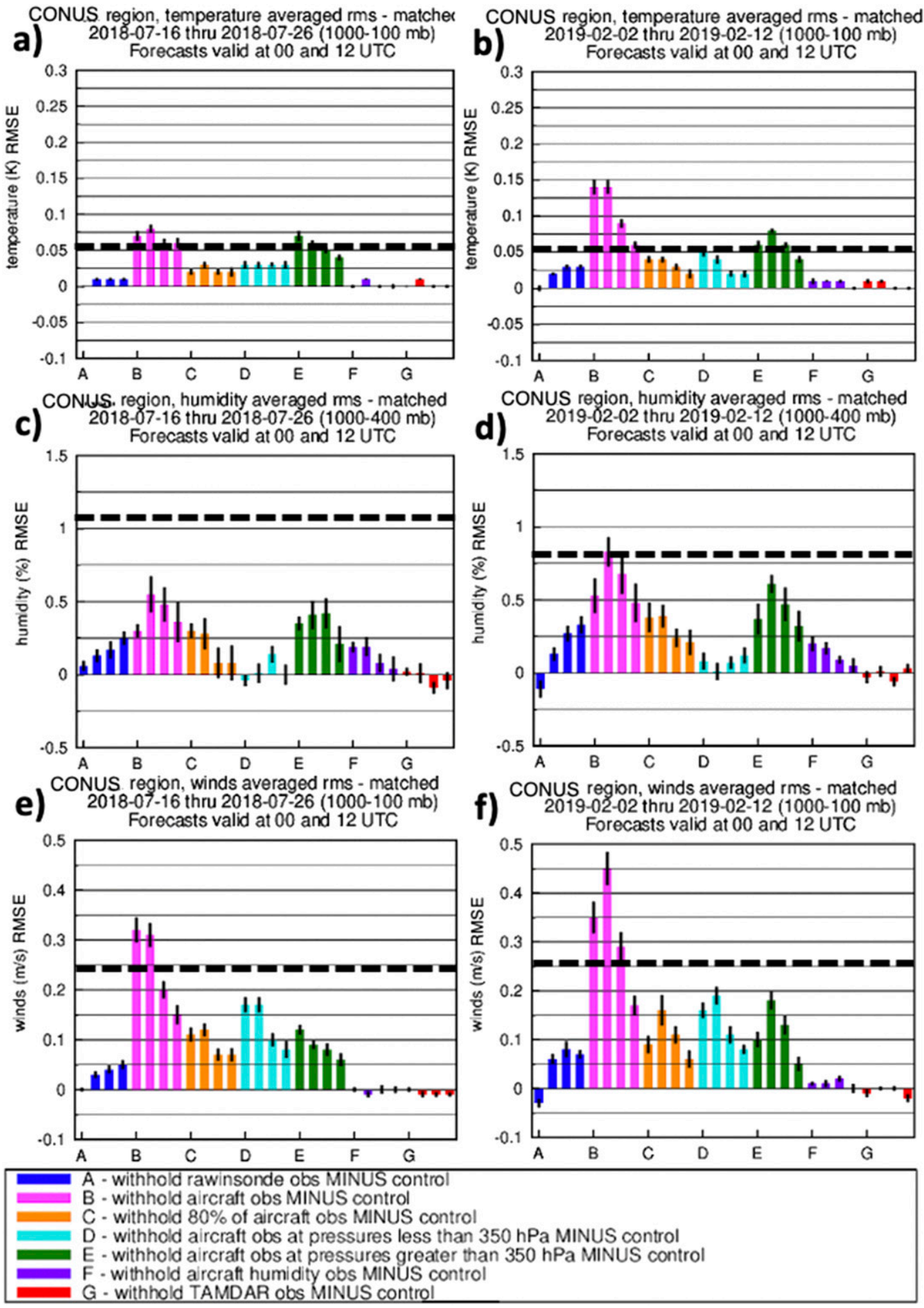

FIG. 11. Differences in RMS error (vs rawinsonde) between observation denial experiments and the control run for (a),(b) 1000-100-hPa temperature (K), (c),(d) 1000-400-hPa relative humidity (\%), and (e),(f) 1000-100-hPa vector wind $\left(\mathrm{m} \mathrm{s}^{-1}\right)$ for the CONUS domain for (left) summer and (right) winter. Results for each of the observational data denial experiments are coded with a different color [raobs, blue; all aircraft, pink; $80 \%$ of aircraft obs, orange; aircraft at pressures less than $350 \mathrm{hPa}$ cyan; aircraft at pressures greater than $350 \mathrm{hPa}$, green; aircraft moisture, purple; TAMDAR, red]. Four adjacent bars are shown for each OSE for 3-, 6-, 9-, and 12-h forecasts. Statistical uncertainties are indicated for each OSE by the narrow black vertical lines showing \pm 1 standard error from the mean impact. In addition, an approximation of $25 \%$ of the maximum possible forecast impact is shown by the dashed horizontal lines in each panel (see the text for details). 


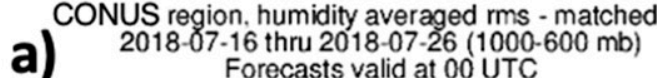

a)

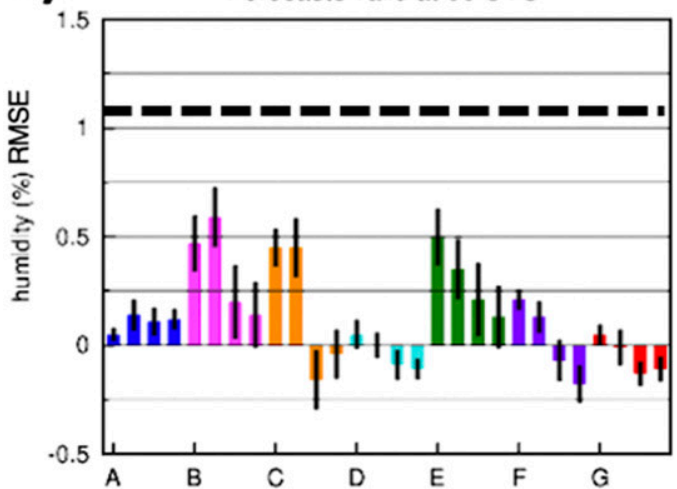

CONUS region, humidity averaged $\mathrm{rms}$ - matched C) $2018-07-16$ thru $2018-07-25(1000-600 \mathrm{mb})$

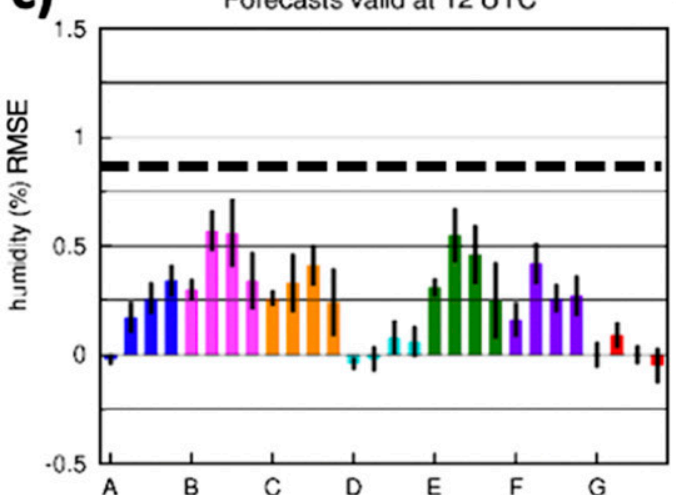

CONUS region, humidity averaged $\mathrm{rms}$ - matched

e) $2018-07-16$ thru $2018-07-26(1000-600 \mathrm{mb})$

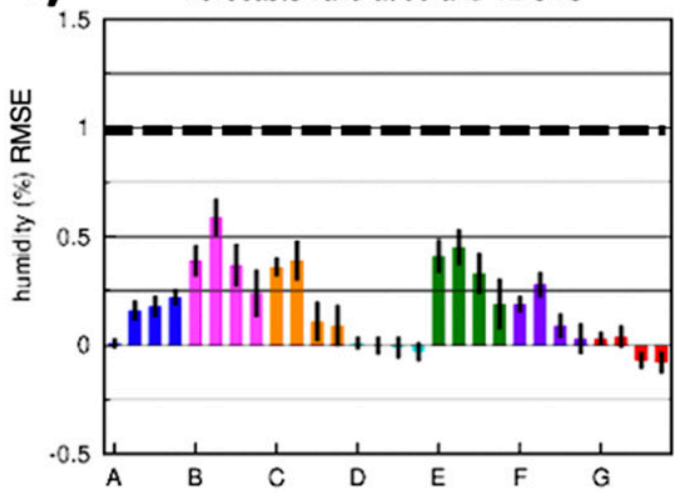

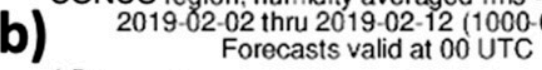

CONUS region, humidity averaged rms - matched

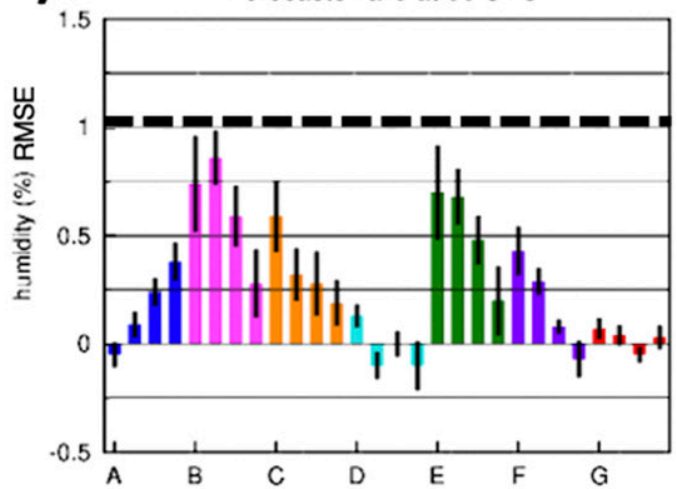

CONUS region, humidity averaged $\mathrm{rms}$ - matched d) 2019-02-02 thru 2019-02-11 (1000-600 mb)

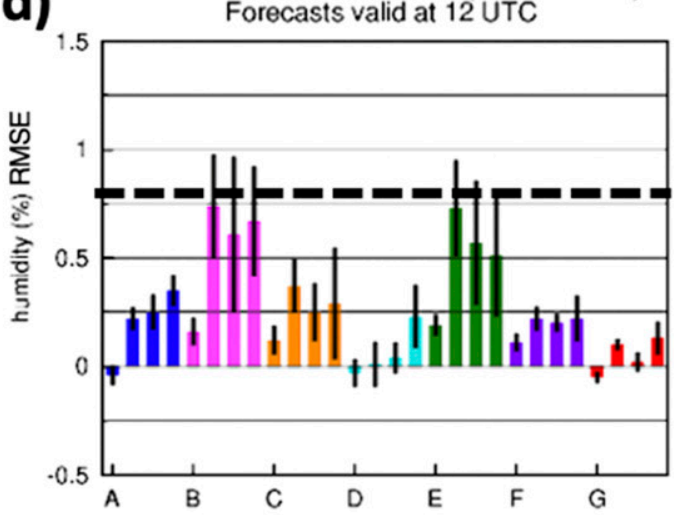

CONUS region, humidity averaged rms - matched f) $\quad 2019-02-02$ thru $2019-02-12(1000-600 \mathrm{mb})$ Forecasts valid at 00 and 12 UTC

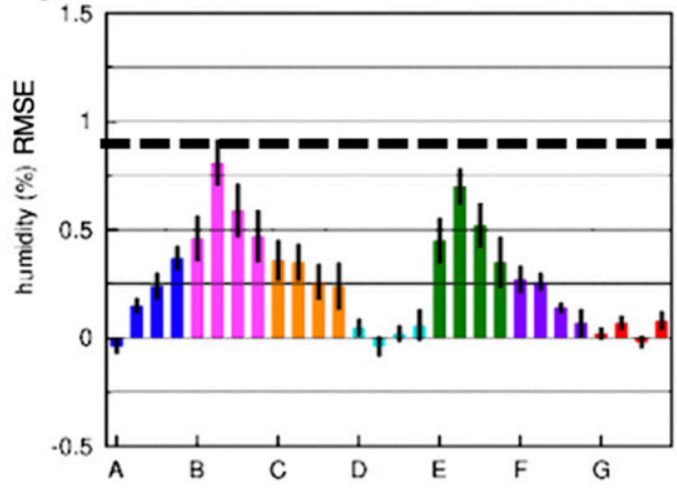

A - withhoid rawnsonde obs MINUS control

B - withhoid aircraft obs MINUS control

C - withhoid $80 \%$ of aircraft obs MINUS control

D - withhoid a rcraft obs at pressures less than $350 \mathrm{hPa}$ MINUS control

E - withhoid aircraft obs at pressures greater than $350 \mathrm{hPa}$ MINUS control

F - withhold arcraft humidity obs MINUS control

G - withhold TAMDAR obs MINUS control

FIG. 12. Similar to Fig. 11, but showing only 1000-600-hPa relative humidity (\%). Forecasts are grouped by verification time: valid at (a),(b) 0000 UTC; (c),(d) 1200 UTC; and (e),(f) both. 

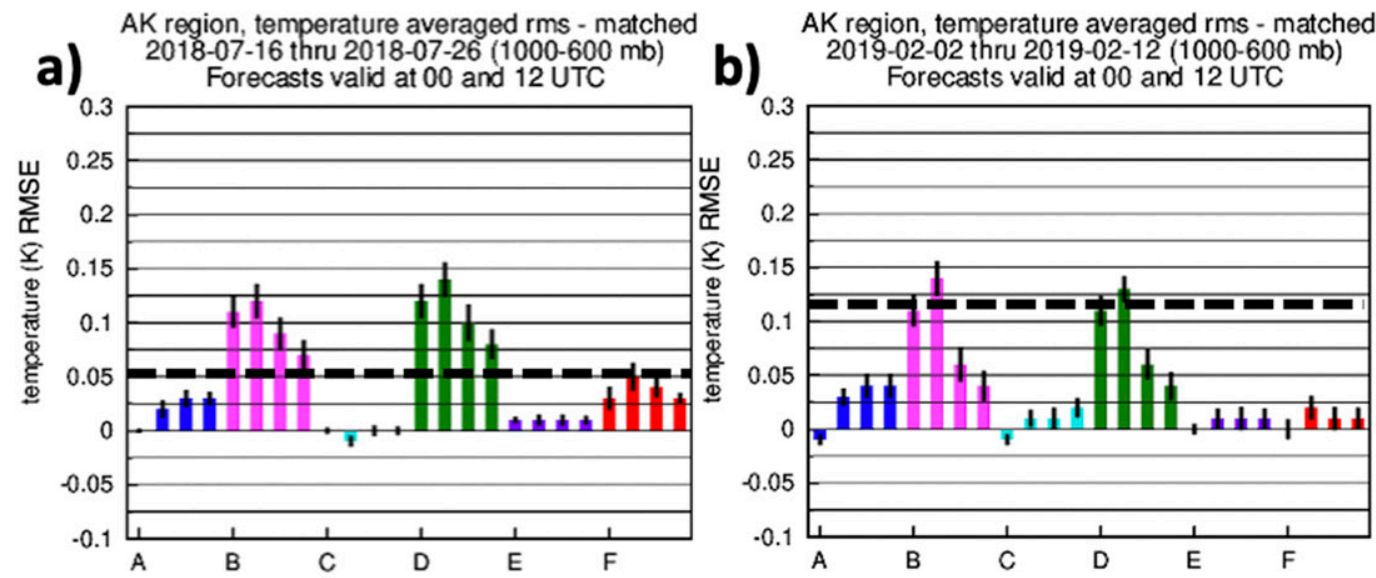

AK region, humidity averaged rms - matched C) 2018-07-16 thru $2018-07-26(1000-600 \mathrm{mb})$
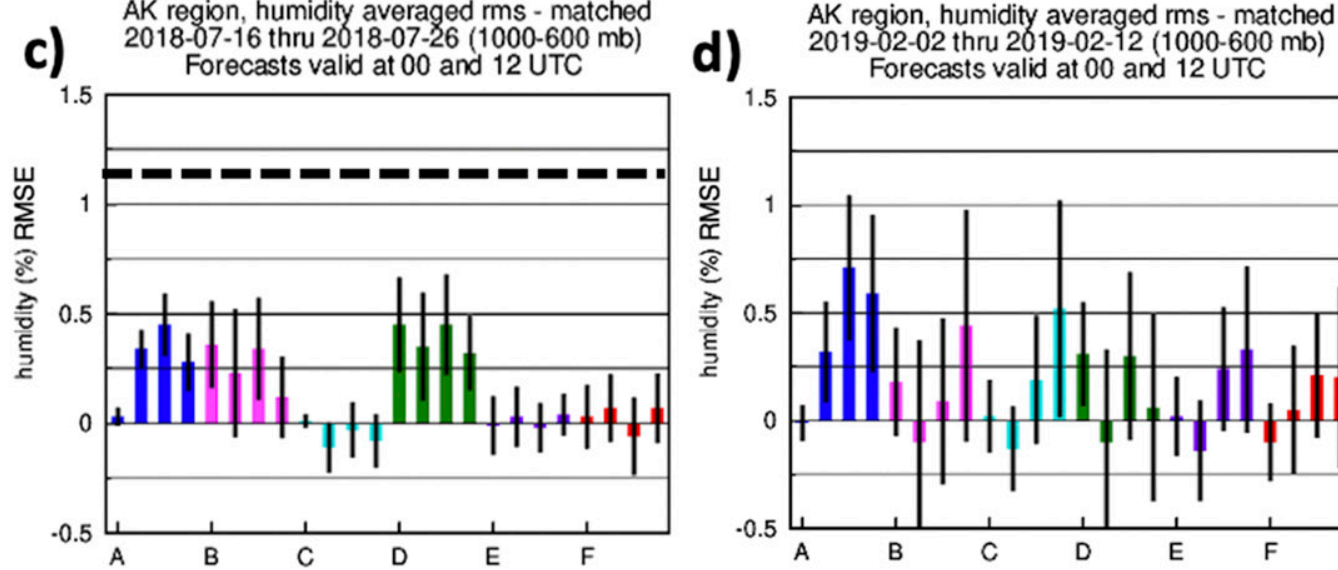
d) 2019-02-02 thru 2019-02-12 (1000-600 mb)
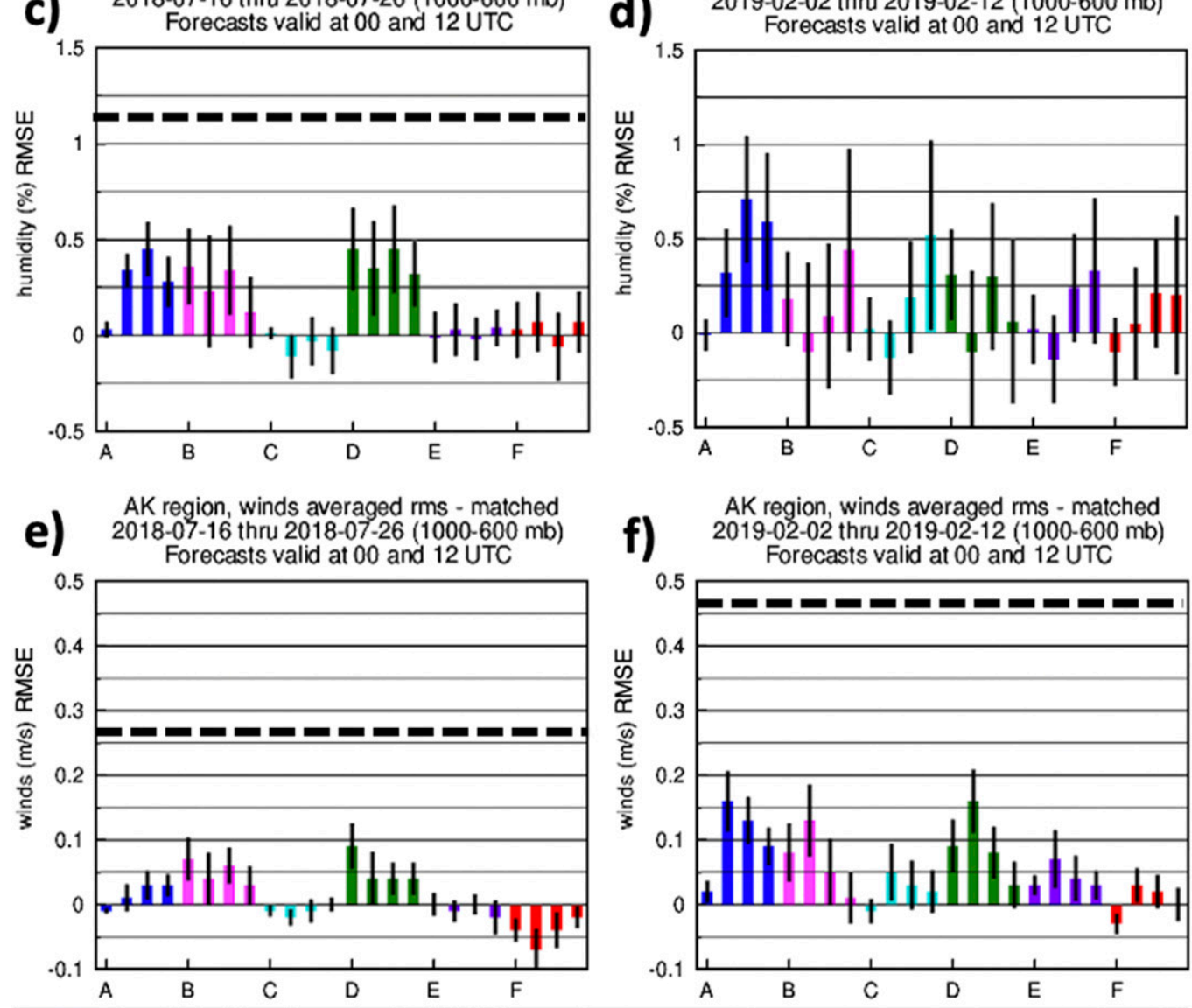

B - withhold aircraft obs MINUS control

C - withhold aircraft obs at pressures less than $350 \mathrm{hPa}$ MINUS control

D - withhold aircraft obs at pressures greater than $350 \mathrm{hPa}$ MINUS control

E - withhold aircraft humidity obs MINUS control

F - withhold TAMDAR obs MINUS control

FIG. 13. Similar to Fig. 11, but for the Alaska domain, excluding the $80 \%$ aircraft obs data denial experiment and showing variables only in the $1000-600$-hPa layer. 
for all variables in the summer (Figs. 13a,c,e), and for temperature and wind forecasts in the winter (Figs. 13b,f). Aircraft moisture observations (purple bars) contribute very little to forecast skill in this region, perhaps because not many aircraft are equipped with these sensors. The TAMDAR observations (red bars), on the other hand, do have an impact upon temperature forecasts, with larger impacts in the summer than in the winter (Figs. 13a,b). It is possible that this is a signal of seasonal flight service during the summer, with more limited spatial coverage of flights in the winter. The small negative impact of TAMDAR observations upon wind forecasts raises the question of observation quality. Alaska is a region of much more complex terrain than the CONUS domain; it is possible that the spatial scale of the RAP data assimilation is too coarse to permit accurate initialization of terrainrelated flows near complex terrain. Most ABO in the Alaska region is focused in southern Alaska (Fig. 1), which is particularly mountainous. TAMDAR observation impacts for wind forecasts over the RAP domain and the CONUS domain are neutral (Figs. 11, 12).

The results of the reduced-ABO experiment are not shown here, because the experiment was designed only to exclude $80 \%$ of aircraft observations over the entire RAP domain, and the fractional $\mathrm{ABO}$ reduction over the Alaska region is likely different. However, Fig. 13 demonstrates the dominant importance of ascent/descent observations over Alaska (green bars; also seen over the CONUS domain for temperature and relative humidity, Figs. 11 and 12), highlighting the opportunity to improve forecasts further by obtaining more aircraft ascent and descent observations over data sparse regions (e.g., Figs. 4, 8).

Overall, ABO contribute statistically significantly to forecast skill for both the CONUS and Alaska regions for wind, temperature, and RH. To our knowledge, this is the first study to examine $\mathrm{ABO}$ impact specifically for Alaska. ABO impact in these regional model forecasts generally decreased with forecast duration but impact was often stronger for $6 \mathrm{~h}$ than for $3 \mathrm{~h}$ forecasts, since $6 \mathrm{~h}$ forecasts had longer exposure to observations in the assimilation cycle due to the partial cycling (Fig. 10, earlier discussion). ABO impacts normalized to maximum possible forecast error reduction ranged from $5 \%$ to $55 \%$ for 6 -h forecasts, and larger over CONUS. An $80 \%$ (not full) reduction in ABO volume, mimicking the 2020 reduction in $\mathrm{ABO}$ volume due to COVID-19, was shown to produce a somewhat smaller but still statistically significant increase in forecast error in these controlled experiments.

\section{Conclusions}

There is consensus among NWP centers around the world that $\mathrm{ABO}$ are one of several most important, if not the single most important, source of weather observations for shortrange NWP. Given this critical importance, it is vital to continue to monitor their spatial and temporal coverage around the globe. Only thus can we identify regions where coverage is lacking and develop strategies to address gaps in a way that provides the most benefit for NWP. As we consider the state of $\mathrm{ABO}$ coverage in the current observing system, it is important to keep in mind the complex nonlinearity of the system. The current coverage of observations (ABO and other types of observations) is very irregular in space and time. In addition, NWP forecast skill is regionally and temporally variable; some of this variability is not due to observation coverage, but rather to meteorological factors (e.g., the presence of deep, moist convection, or shallow Arctic clouds). Thus, it is unclear what will be the magnitude of the impact of assimilating new observations in a certain region of the globe without undertaking quantitative NWP experiments [data denial or sensitivity experiments, or observation sensitivity simulation experiments (OSSEs)]. However, the temporal and spatial coverage of $\mathrm{ABO}$ is an important component of the overall NWP impact.

ABO coverage described in this article agrees broadly with that shown by previous studies. The greatest coverage temporally and spatially is in the densely trafficked regions of the United States and Europe, with secondary maxima in East Asia, eastern Australia, and coastal South America. Even within the most well-observed regions, most coverage consists of cruising aircraft, with relatively fewer vertical profiles coming from ascending or descending flights. Globally, vertical profile observations are confined to the immediate vicinity of airports. Large portions of the globe remain virtually unobserved, particularly in the Southern Hemisphere. In the North American region, much of Canada has relatively sparse coverage of $\mathrm{ABO}$. This suggests that acquiring new observations from aircraft servicing smaller airports in Canada, particularly in the Arctic, could be highly valuable. A large proportion of travel in the Arctic is dependent upon aircraft; however, many of these aircraft are relatively small and not part of a larger fleet that is outfitted with temperature/wind/humidity sensors.

The COVID-19 pandemic has led to a real-time partial data denial experiment for global NWP, with ABO coverage reduced by $75 \%$ globally by late April 2020 . Although the impacts of this decrease in ABO coverage are not expected to be as severe as seen during, for example, 11-13 September 2001 when all U.S. aircraft were grounded (Benjamin 2007), we still expect some impact upon forecast skill. We have quantified the impact of an $80 \%$ reduction in ABO coverage with two 10-day retrospective experiments with the RAP NWP system. If the relationship between observation coverage and forecast impacts were linear, we would expect the reduced-ABO experiment to exhibit $80 \%$ of the degradation seen in the no-ABO experiment. Our results reveal that the degradation seen in the reduced-ABO experiment is less than $80 \%$. In particular, we find that the reduced-ABO temperature impact over the CONUS domain is approximately $30 \%$ of the no-ABO impact (Figs. 11a,b), the reduced-ABO RH impact is $50 \%-60 \%$ of the no-ABO impact (Figs. 11c,d), and the reduced-ABO wind impact is $35 \%-40 \%$ of the no-ABO impact (Figs. 11e,f). These experiments represent the first quantification of the forecast impact of the COVID-19 flight reductions.

There are significant opportunities for expansion of $\mathrm{ABO}$ coverage in the coming decade, taking advantage of new aircraft surveillance technologies. Mode-S has already been used effectively within European short-range NWP systems (e.g., by the Met Office; Gustafsson et al. 2018), with a documented 
positive impact across seasons upon 1-3-h forecasts (Strajnar et al. 2015; Lange and Janjić 2016). Assimilation of these data within the United States is a major opportunity for advancing NWP forecast skill for short-range forecasting. In addition, ADS-B and ADS-C observations are becoming available over much of the globe now, and investigation is ongoing into the measurement of meteorological variables by unoccupied aerial vehicles (UAVs; e.g., Shimura et al. 2018). A high priority should be placed upon examining the quality and testing the impact of assimilating these new types of ABO within rapidly updating NWP systems such as the RAP and HRRR.

Acknowledgments. Support for this research was provided by the FAA (project DTFAWA-10-X-80020). Eric James is supported by funding from NOAA Award NA17OAR4320101, and Brian Jamison is supported by funding from NOAA Award NA14OAR4320125. We thank William Moninger of NOAA/OAR/ESRL/GSL for providing a helpful review of an earlier draft of this paper and also for his expertise with regard to the aircraft observation database used herein.

Data availability statement. The aircraft observations used in this research are housed within the NOAA Earth System Research Laboratory/Global Systems Division AMDAR database. The observations are proprietary to the airlines providing the data, and thus the distribution of real-time data is restricted. More information is provided online (https:// amdar.noaa.gov/FAQ.html).

\section{REFERENCES}

Auligné, T., and Coauthors, 2016: Forecast Sensitivity and Observation Impact (FSOI) Inter-Comparison Experiment. Sixth WMO Workshop on the Impact of Various Observation Systems on NWP, Shanghai, China, NWP, WS6-2016-081, https://www.wmo.int/pages/prog/www/WIGOS-WIS/reports/ 6NWP_Shanghai2016/Session-3/3.4.pptx.

Ballish, B. A., and V. K. Kumar, 2008: Systematic differences in aircraft and radiosonde temperatures. Bull. Amer. Meteor. Soc., 89, 1689-1708, https://doi.org/10.1175/2008BAMS2332.1.

Benjamin, S. G., 2007: Numerical model applications and impact for aircraft observations. Short Course on Meteorological Applications of Aircraft Weather Data, San Antonio, TX, Amer. Meteor. Soc., https://amdar.noaa.gov/2007course/ Benjamin.ppt.

_ , K. A. Brewster, R. Brümmer, B. F. Jewett, T. W. Schlatter, T. L. Smith, and P. A. Stamus, 1991: An isentropic threehourly data assimilation system using ACARS aircraft observations. Mon. Wea. Rev., 119, 888-906, https://doi.org/ 10.1175/1520-0493(1991)119<0888:AITHDA > 2.0.CO;2.

_ B. E. Schwartz, and R. E. Cole, 1999: Accuracy of ACARS wind and temperature observations determined by collocation. Wea. Forecasting, 14, 1032-1038, https://doi.org/10.1175/ 1520-0434(1999)014<1032:AOAWAT>2.0.CO;2..

—- and Coauthors, 2004: An hourly assimilation-forecast cycle: The RUC. Mon. Wea. Rev., 132, 495-518, https://doi.org/ 10.1175/1520-0493(2004)132<0495:AHACTR>2.0.CO;2.

_, B. D. Jamison, W. R. Moninger, S. R. Sahm, B. E. Schwartz, and T. W. Schlatter, 2010: Relative short-range forecast impact from aircraft, profiler, radiosonde, VAD, GPS-PW, METAR, and mesonet observations via the RUC hourly assimilation cycle. Mon. Wea. Rev., 138, 1319-1343, https:// doi.org/10.1175/2009MWR3097.1.

_ , and Coauthors, 2016: A North American hourly assimilation and model forecast cycle: The Rapid Refresh. Mon. Wea. Rev., 144, 1669-1694, https://doi.org/10.1175/MWR-D-15-0242.1.

Buehner, M., P. Du, and J. Bédard, 2018: A new approach for estimating the observation impact in ensemble-variational data assimilation. Mon. Wea. Rev., 146, 447-465, https://doi.org/ 10.1175/MWR-D-17-0252.1.

Cardinali, C., 2009: Monitoring the observation impact on the short-range forecast. Quart. J. Roy. Meteor. Soc., 135, 239-250, https://doi.org/10.1002/qj.366.

Chen, Y., 2020: COVID-19 pandemic imperils weather forecast. Geophys. Res. Lett., 47, e2020GL088613, https://doi.org/10.1029/ 2020GL088613.

Daniels, T. S., W. R. Moninger, and R. D. Mamrosh, 2006: Tropospheric Airborne Meteorological Data Reporting (TAMDAR) overview. 10th Symp. on Integrated Observing and Assimilating Systems for Atmosphere, Oceans, and Land Surface, Atlanta, GA, Amer. Meteor. Soc., 9.1, https://ams.confex.com/ams/pdfpapers/ 104773.pdf.

de Haan, S., 2011: High-resolution wind and temperature observations from aircraft tracked by Mode-S air traffic control radar. J. Geophys. Res., 116, D10111, https://doi.org/10.1029/ 2010JD015264.

- , and A. Stoffelen, 2012: Assimilation of high-resolution Mode-S wind and temperature observations in a regional NWP model for nowcasting applications. Wea. Forecasting, 27, 918-937, https://doi.org/10.1175/WAF-D-11-00088.1.

Ding, J., X. Zhuge, X. Li, Z. Yuan, and Y. Wang, 2018: Evaluation of accuracy of Chinese AMDAR data for 2015. J. Atmos. Oceanic Technol., 35, 943-951, https://doi.org/10.1175/JTECH-D17-0095.1.

Drüe, C., W. Frey, A. Hoff, and T. Hauf, 2008: Aircraft-specific errors in AMDAR weather reports from commercial aircraft. Quart. J. Roy. Meteor. Soc., 134, 229-239, https://doi.org/10.1002/qj.205.

ECMWF, 2020: Drop in aircraft observations could have impact on weather forecasts. ECMWF, https://www.ecmwf.int/en/about/ media-centre/news/2020/drop-aircraft-observations-could-haveimpact-weather-forecasts.

EUMETNET, 2015: E-AMDAR. Accessed 10 January 2020, http://www.eumetnet.eu/e-amdar.

FAA, 2010: Automatic Dependent Surveillance-Broadcast (ADS-B) out performance requirements to support Air Traffic Control (ATC) service; final rule. 14 CFR Part 91, Part III, Department of Transportation, Federal Register, Vol. 75, 30159-30195, https://www.govinfo.gov/content/pkg/FR-2010-05-28/pdf/201012645.pdf.

Fleming, R. J., 1996: The use of commercial aircraft as platforms for environmental measurements. Bull. Amer. Meteor. Soc., 77, 2229-2242, https://doi.org/10.1175/1520-0477(1996)077<2229: TUOCAA $>2.0 . \mathrm{CO} ; 2$.

Gustafsson, N., and Coauthors, 2018: Survey of data assimilation methods for convective-scale numerical weather prediction at operational centres. Quart. J. Roy. Meteor. Soc., 144, 12181256, https://doi.org/10.1002/qj.3179.

Henson, B., C. Dolce, and B. Donegan, 2020: Fewer people are flying because of the Coronavirus-And that is affecting the quality of your weather forecast. Weather Channel, https:// weather.com/health/coronavirus/news/2020-03-24-fewer-peopleflying-might-affect-quality-weather-forecasts.

Hoover, B. T., D. A. Santek, A.-S. Dalox, Y. Zhong, R. Dworak, and R. A. Petersen, 2017: Forecast impact of assimilating 
aircraft WVSS-II water vapor mixing ratio observations in the Global Data Assimilation System (GDAS). Wea. Forecasting, 32, 1603-1611, https://doi.org/10.1175/WAF-D-16-0202.1.

James, E. P., and S. G. Benjamin, 2017: Observation system experiments with the hourly updating Rapid Refresh model using GSI hybrid ensemble-variational data assimilation. Mon. Wea. Rev., 145, 2897-2918, https://doi.org/10.1175/ MWR-D-16-0398.1.

Jamison, B., and W. R. Moninger, 2002: An analysis of the temporal and spatial distribution of ACARS data in support of the TAMDAR program. 10th Conf. on Aviation, Range, and Aerospace Meteorology, Portland, OR, Amer. Meteor. Soc., J1.9, https://ams.confex.com/ams/pdfpapers/39900.pdf.

Kalnay, E., 2002: Atmospheric Modeling, Data Assimilation and Predictability. Cambridge University Press, 368 pp.

Lange, H., and T. Janjić, 2016: Assimilation of Mode-S EHS aircraft observations in COSMO-KENDA. Mon. Wea. Rev., 144, 1697-1711, https://doi.org/10.1175/MWR-D-15-0112.1.

Langland, R. H., and N. L. Baker, 2004: Estimation of observation impact using the NRL Atmospheric Variational Data Assimilation Adjoint System. Tellus, 56A, 189-201, https:// doi.org/10.3402/tellusa.v56i3.14413.

Lorenc, A. C., and R. T. Marriott, 2013: Forecast sensitivity to observations in the Met Office global numerical weather prediction system. Quart. J. Roy. Meteor. Soc., 140, 209-224, https://doi.org/10.1002/qj.2122.

Met Office, 2019: Assimilation of new low-cost wind observations from aircraft. Met Office, https://www.metoffice.gov.uk/research/ news/2019/assimilation-of-mode-s-observations-in-ukv.

Moninger, W. R., R. D. Mamrosh, and P. M. Pauley, 2003: Automated meteorological reports from commercial aircraft. Bull. Amer. Meteor. Soc., 84, 203-216, https://doi.org/10.1175/ BAMS-84-2-203.

—, S. G. Benjamin, B. D. Jamison, T. W. Schlatter, T. L. Smith, and E. J. Szoke, 2010: Evaluation of regional aircraft observations using TAMDAR. Wea. Forecasting, 25, 627-645, https://doi.org/10.1175/2009WAF2222321.1.

Petersen, R. A., 2016: On the impact and benefits of AMDAR observations in operational forecasting-Part I: A review of the impacts of automated wind and temperature reports. Bull. Amer. Meteor. Soc., 97, 585-602, https://doi.org/10.1175/ BAMS-D-14-00055.1.
— L. Cronce, R. Mamrosh, R. Baker, and P. Pauley, 2016: On the impact and future benefits of AMDAR observations in operational forecasting-Part II: Water vapor observations. Bull. Amer. Meteor. Soc., 97, 2117-2133, https://doi.org/ 10.1175/BAMS-D-14-00211.1.

Shimura, T., M. Inoue, H. Tsujimoto, K. Sasaki, and M. Iguchi, 2018: Estimation of wind vector profile using a hexarotor unmanned aerial vehicle and its application to Meteorological observation up to $1000 \mathrm{~m}$ above surface. J. Atmos. Oceanic Technol., 35, 1621-1631, https://doi.org/10.1175/JTECH-D17-0186.1.

Stone, E. K., and G. Pearce, 2016: A network of Mode-S receivers for routine acquisition of aircraft-derived meteorological data. J. Atmos. Oceanic Technol., 33, 757-768, https://doi.org/ 10.1175/JTECH-D-15-0184.1.

Strajnar, B., 2012: Validation of Mode-S meteorological routine air report aircraft observations. J. Geophys. Res., 117, D23110, https://doi.org/10.1029/2012JD018315.

—_, N. Zagar, and L. Berre, 2015: Impact of new aircraft observations Mode-S MRAR in a mesoscale NWP model. J. Geophys. Res. Atmos., 120, 3920-3938, https://doi.org/10.1002/ 2014JD022654.

WMO, 2003: Aircraft Meteorological Data Relay (AMDAR) reference manual. WMO Doc. 958, 84 pp., https://www.wmo.int/ pages/prog/www/GOS/ABO/AMDAR//publications/AMDAR_ Reference_Manual_2003.pdf.

2015: The WMO Regional Workshop on AMDAR in Nairobi, Kenya. AMDAR Observing Newsletter. Vol. 10, WMO, https://sites.google.com/a/wmo.int/amdar-news-andevents/newsletters/volume-10-october-2015.

- 2019: Aircraft-based observations data. WMO, accessed 23 December 2019, https://www.wmo.int/pages/prog/www/GOS/ ABO/ABO_Data.html.

Zhang, X., H. Wang, X.-Y. Huang, F. Gao, and N. Jacobs, 2015: Using adjoint-based forecast sensitivity method to evaluate TAMDAR data impacts on regional forecasts. Adv. Meteor., 2015, 427616, https://doi.org/10.1155/2015/427616.

Zhu, Y., J. C. Derber, R. J. Purser, B. A. Ballish, and J. Whiting, 2015: Variational correction of aircraft temperature bias in the NCEP's GSI analysis system. Mon. Wea. Rev., 143, 3774-3803, https://doi.org/10.1175/MWRD-14-00235.1. 